\title{
A Novel Parameterization of Snow Albedo Based on a Two-Layer Snow Model with a Mixture of Grain Habits
}

\author{
MASANORI SAITO AND PING YANG \\ Department of Atmospheric Sciences, Texas A\&M University, College Station, Texas \\ NORMAN G. LOEB AND SEIJI KATO \\ NASA Langley Research Center, Hampton, Virginia
}

(Manuscript received 12 October 2018, in final form 25 February 2019)

\begin{abstract}
Snow albedo plays a critical role in the surface energy budget in snow-covered regions and is subject to large uncertainty due to variable physical and optical characteristics of snow. We develop an optically and microphysically consistent snow grain habit mixture (SGHM) model, aiming at an improved representation of bulk snow properties in conjunction with considering the particle size distribution, particle shape, and internally mixed black carbon (BC). Spectral snow albedos computed with two snow layers with the SGHM model implemented in an adding-doubling radiative transfer model agree with observations. Top-snow-layer optical properties essentially determine spectral snow albedo when the top-layer snow water equivalent (SWE) is large. When the top-layer SWE is less than $1 \mathrm{~mm}$, the second-snow-layer optical properties have nonnegligible impacts on the albedo of the snow surface. Snow albedo enhancement with increasing solar zenith angle (SZA) largely depends on snow particle effective radius and also internally mixed BC. Based on the SGHM model and various sensitivity studies, single- and two-layer snow albedos are parameterized for six spectral bands used in NASA Langley Research Center's modified Fu-Liou broadband radiative transfer model. Parameterized albedo is expressed as a function of snow particle effective radii of the two layers, SWE in the top layer, internally mixed BC mass fraction in both layers, and SZA. Both single-layer and two-layer parameterizations provide band-mean snow albedo consistent with rigorous calculations, achieving correlation coefficients close to 0.99 for all bands.
\end{abstract}

\section{Introduction}

Snow plays an essential role in the surface radiation balance as well as the hydrological cycle through complex snow-atmosphere feedbacks (Randall et al. 1994). In particular, surface albedo is one of the main regulators of the radiative balance over snow-covered areas. Even with a persisting snow cover, changes in snow albedo affect air temperature, snow-cover extent, and the melting of snow. Therefore, an accurate snow albedo model in conjunction with a physical snow-layer model should be incorporated into general circulation models (GCMs) to obtain more accurate climate projections. Surface albedo of snow is generally much higher than that of land or ocean, and has significant variability associated with snow particle size (e.g., Wiscombe and

\footnotetext{
Corresponding author: Dr. Masanori Saito, masa.saito@ tamu.edu
}

Warren 1980), shape (e.g., Jin et al. 2008; He et al. 2017b), impurity (e.g., Warren and Wiscombe 1980; Aoki et al. 2000, hereafter A00), and solar zenith angle (SZA; e.g., Grenfell et al. 1994). Among these factors, snow particle size is the primary factor that determines snow albedo, particularly in the near-infrared regime (Warren 1982; Aoki et al. 2003).

Warren and Wiscombe (1980) found that absorptive impurities in snow such as mineral dust, organic carbon, and soot [i.e., black carbon (BC) particles] are the primary factors determining snow albedo at visible wavelengths. Several previous studies revealed that, among the three types of absorbing impurities, BC usually accounts for $50 \%-80 \%$ of the total light absorption by snow at visible wavelengths, with the highest proportion in areas with substantial industrial pollution (e.g., Doherty et al. 2010; Wang et al. 2013; Dang et al. 2017). Therefore, BC is considered to be the primary source of light absorption in 
most snow-covered regions. In addition, BC in snow significantly affects the local surface radiation budget, especially in the Northern Hemisphere. Hansen and Nazarenko (2004) estimate that BC in snow yields a climate forcing of $+0.3 \mathrm{~W} \mathrm{~m}^{-2}$ in the Northern Hemisphere, and this forcing is twice as efficient as that associated with $\mathrm{CO}_{2}$. Flanner et al. (2012) point out that internally mixed $\mathrm{BC}$ enhances snow absorption efficiency at visible wavelengths by a factor of $1.8-2.1$ compared with externally mixed BCs. Since internal mixing of $\mathrm{BC}$ in snow particles can affect many atmospheric processes such as ice nucleation, scavenging, and a combination of dry deposition over surface snow and melting and refreezing of snow, absorbing particles including BC should be taken into account in snow albedo simulations.

Snow particle shape variation also leads to uncertainty in snow albedo. In previous studies, snow particles were often assumed to be spherical particles for computational simplicity. However, many accumulated snow-sampling studies demonstrate that accumulated snow particles are typically nonspherical. Moreover, the particle shapes and sizes vary over time due to snow metamorphosis (e.g., Nakamura et al. 2001, hereafter N01). As snow cover persists, snow particle edges are gradually smoothed and the particles become more compact but are still in irregular shapes (Ishimoto et al. 2018, hereafter I18). Snow particle shape is an important factor determining albedo. Different particle shapes with the same effective radius have different mean particle volumes, causing different particle absorption. The asymmetry parameters of typical snow particles range from 0.75 to 0.9 , depending on the particle shape. Jin et al. (2008) demonstrate a nonnegligible effect of snow particle shape on visible snow albedo due to the variation of the asymmetry parameter. A snow particle shape with a low asymmetry parameter provides high visible snow albedo (Dang et al. 2016). Furthermore, snow albedo based on nonspherical snow particles with internally mixed $\mathrm{BC}$ has moderate sensitivity to snow particle shape (He et al. 2018c).

In addition to snow particle morphological characteristics, the vertically inhomogeneous variation of snow particle size affects spectral snow albedo. The snow cover may contain many layers accumulated over several months, with varying factors affecting snow layers between snowfalls such as melting, refreezing, and sublimation. With a snowfall over a snow cover, snow contains at least two layers: newly accumulated "fresh" snow in the top layer and preaccumulated "aged" snow in the bottom layer. Grenfell et al. (1994) demonstrate that simulated spectral snow albedo based on a two-layer assumption is more consistent with observations than the counterpart based on a single-layer snow assumption. This is fundamentally due to the variation of the penetration depth of the incident solar radiation with wavelength (Zhou et al. 2003; Aoki et al. 2011). Based on these facts, a two-layer snow model was used to remote sensing applications regarding characterizing snow microphysical properties (Jin et al. 2008).

To efficiently compute snow albedo in GCMs with a snow forecast model, numerous snow albedo parameterizations have been developed (e.g., Marshall and Oglesby 1994; Yasunari et al. 2011). Although most snow albedo parameterizations consider snow particle size, and some consider snow impurity (Dang et al. 2015), particle shape (He et al. 2018c), or SZA (Gardner and Sharp 2010), none of the previous snow albedo parameterizations accounts for all these variables under the condition of two snow layers. In particular, simple snow albedo parameterizations assume a single snow layer to minimize the computational demand in dealing with snow albedo in GCMs, regardless of the fact that sophisticated land surface schemes in climate models do consider multiple snow layers (e.g., Molod et al. 2015; Saha et al. 2017). For rigorous snow albedo calculations for GCMs, a two-layer snow albedo parameterization is necessary to further improve the accuracy of snow albedo simulations as well as surface energy budget estimates over snow-covered regions.

Because of the need for a better representation of snow albedo, this study first describes a snow grain habit mixture (SGHM) model, a newly developed snow particle model based on in situ accumulated snow measurements. Using the SGHM, we demonstrate improvement in calculating rigorous spectral snow albedo due to a twolayer snow assumption. Finally, we also develop a twolayer snow albedo parameterization that is useful for rapid broadband shortwave radiative transfer calculation in weather forecasting and climate models.

Table 1 lists acronyms. Section 2 describes the methods for single-scattering calculation, snow albedo simulation, and definitions of variables to be used for parameterization. Section 3 discusses and validates the SGHM model. Section 4 provides rigorous spectral surface albedo simulations and sensitivity studies based on the two-layer snow-cover assumption. Section 5 presents development and evaluation of the present single-layer and two-layer snow albedo parameterizations. Section 6 summarizes the findings and conclusions of this study.

\section{Methods}

\section{a. Optical property calculations of snow particles}

The single-scattering properties of snow particles are fundamental to the computation of snow albedo. Realistic snow and ice particles are nonspherical and have 
TABLE 1 . The list of acronyms.

\begin{tabular}{ll}
\hline \multicolumn{1}{c}{ Acronyms } & \multicolumn{1}{c}{ Meaning } \\
\hline A00 & Aoki et al. (2000) \\
N01 & Nakamura et al. (2001) \\
I18 & Ishimoto et al. (2018) \\
BC & Black carbon particles \\
PSD & Particle size distribution \\
SSA & Specific surface area \\
SWE & Snow water equivalent \\
SZA & Solar zenith angle \\
DROX & Droxtal \\
SBUL & Solid bullet rosette \\
SCOL & Solid hexagonal column \\
SGHM & Snow grain habit mixture \\
GCM & General circulation model \\
LaRC-FL RTM & NASA Langley Research Center's modified \\
& Fu-Liou radiative transfer model \\
SNICAR & Snow, Ice, and Aerosol Radiative model \\
\hline
\end{tabular}

inhomogeneous internal structures, and tremendous efforts have been made to calculate the single-scattering properties of ice crystals (e.g., Macke et al. 1996; Liou et al. 2014). The physical geometric optics method was developed and refined to obtain reliable singlescattering properties of nonspherical ice crystals (Yang et al. 2019, and references cited therein). Tang et al. (2017) consider nonspherical particles with spherical particle inclusions using a stochastic approach that is applicable to calculating the single-scattering properties of nonspherical snow particles with internal BC mixing based on an assumption that internally mixed BCs are spherical. In this study, BC impurities on the surface of snow particles are also represented by internally mixed $\mathrm{BC}$ because internally mixed $\mathrm{BC}$ is the primary cause of reduced visible snow albedo (Warren and Wiscombe 1980; He et al. 2017b). The refractive indices of ice and BC used in this study are based on Warren and Brandt (2008) and Stegmann and Yang (2017), respectively. The volume densities are assumed to be $0.917 \mathrm{~g} \mathrm{~cm}^{-3}$ for ice $\rho_{\text {ice }}$ (Wiscombe and Warren 1980) and $1.7 \mathrm{~g} \mathrm{~cm}^{-3}$ for BC (Bond and Bergstrom 2006). Schwarz et al. (2013) show that $\mathrm{BC}$ impurity is larger in snow particles on the surface than in the atmosphere based on direct snow in situ measurements, and the BC PSD has a long tail and deviates from a lognormal distribution. Therefore, the PSD of BC inside snow particles is assumed to be the gamma distribution with an effective radius of $0.1 \mu \mathrm{m}$ and an effective variance of 0.1 . In this study, the singlescattering properties of snow particles are computed for pure snow particles and four levels of impurities (BC mass fractions of $50,100,500$, and $1000 \mathrm{ng} \mathrm{g}^{-1}$ ), with snow particle maximum dimensions ranging from 2 to $10000 \mu \mathrm{m}$. The assumed snow particle shape distribution for snow on the surface is discussed in section $3 a$.

\section{b. Rigorous snow albedo calculations}

To rigorously calculate spectral snow albedo $\alpha_{\lambda}$, we use an adding-doubling radiative transfer model developed by Huang et al. (2015). The wavelength range for spectral snow albedo calculations extends from 0.2 to $5 \mu \mathrm{m}$. The bulk optical properties of snow (section 3a), which are precomputed with the single-scattering properties of individual snow particles, and optical thickness are assigned to each plane-parallel homogeneous snow layer. Note that we assume that the single scattering by particles in densely packed snow is independent. This assumption is widely used for previous snow albedo studies, although it might cause biases in radiative transfer, partially in the backscattering direction due to coherent scattering (Mishchenko et al. 2011) causing an overestimated snow albedo (He et al. 2017a). The bottom snow layer is assumed to be optically thick with an optical thickness of 960, that is, practically semi-infinite. This assumption is valid when the fresh snow layer is deeper than $30 \mathrm{~cm}$, and is more plausible for the snow layer, which includes a considerable amount of impurities (Dang et al. 2016). In the calculation, we assume the surface underneath the snow layer to be black. A broadband radiative transfer model for flux calculations has a finite number of bands in a spectral region, and a radiative transfer equation is solved for each of the bands. To provide broadband snow albedo $\alpha$, we convolute the spectral snow albedo with an approximate mean clear-sky solar spectrum $S_{\lambda}$ for the Northern Hemisphere, obtained from the American Society for Testing and Materials reference dataset (available at https://rredc.nrel.gov/solar/ spectra/am1.5/), expressed by

$$
\alpha=\frac{\int_{\lambda_{\min },}^{\lambda_{\max }} \alpha_{\lambda} s_{\lambda} d \lambda}{\int_{\lambda_{\min }}^{\lambda_{\max }} s_{\lambda} d \lambda},
$$

where $\lambda_{\max }$ and $\lambda_{\min }$ respectively indicate the lower and upper wavelengths of a spectral band. This study does not consider the solar spectrum of a cloudy sky. Note that the effect of cloudiness on snow albedo is insignificant in the visible band, but is substantial in nearinfrared bands that include water or ice absorption (Aoki et al. 1999).

\section{c. Snow albedo parameterizations}

After producing the rigorously calculated snow albedo for various scenarios of snow properties, we develop a two-layer snow albedo parameterization for computational efficiency in GCM applications. The top layer is "fresh" snow with a variable thickness specified in terms 
of SWE, and the bottom layer is "aged" snow. The model variables contain SWE in the top snow layer, snow particle effective radii in the top and bottom snow layers, the cosine of SZA, and the BC mass fraction that is the same in the two snow layers.

The snow particle effective radius $R_{e}$ is defined as

$$
R_{e}=\frac{3 V}{4 A_{\text {proj }}}
$$

where $V$ and $A_{\text {proj }}$ are the particle volume and projected area, respectively. In the literature, other size definitions such as the volume-equivalent sphere radius $R_{V}$ and projected-area-equivalent sphere radius $R_{A}$ are also widely used for snow particle studies, given by

$$
R_{V}=\left(\frac{3 V}{4 \pi}\right)^{1 / 3}
$$

and

$$
R_{A}=\left(\frac{A_{\text {proj }}}{\pi}\right)^{1 / 2} .
$$

The parameter $R_{V}$ can be obtained from particle mass in a straightforward manner (Brandes et al. 2007), and $R_{A}$ is derived from photographic images of snow particles with Eq. (4) (A00). The SSA, defined as the ratio of the total surface area to the mass of a snow particle, is widely used and satisfies $R_{e}=3 /\left(\rho_{\text {ice }} \mathrm{SSA}\right)$ for spherical or convex particles (e.g., spheroids, hexagonal columns, and droxtals). It is not technically easy to directly measure SSA. Therefore, this study does not consider a conversion from SSA to $R_{e}$ but provides conversions from $R_{V}$ and $R_{A}$ to $R_{e}$ to enhance usability of these parameterizations. In this study, we consider the six spectral bands involved in LaRC-FL RTM (Fu and Liou 1993; Kratz and Rose 1999; Kato et al. 1999, 2005), which spectrally covers $0.2-4 \mu \mathrm{m}$.

\section{Bulk optical properties of the SGHM model}

This section presents the SGHM model developed based on previous in situ measurements of snow on the surface. In addition, detailed descriptions of the SGHM model treatment of particle shape (section 3a), PSD (section $3 \mathrm{~b}$ ), and internally mixed $\mathrm{BC}$ (section 3c) are presented. The bulk optical properties of the SGHM model are evaluated in section $3 \mathrm{~d}$.

\section{a. Snow particle habit mixtures}

Many snow albedo schemes and parameterizations assume spherical snow particles (e.g., Dang et al. 2015)

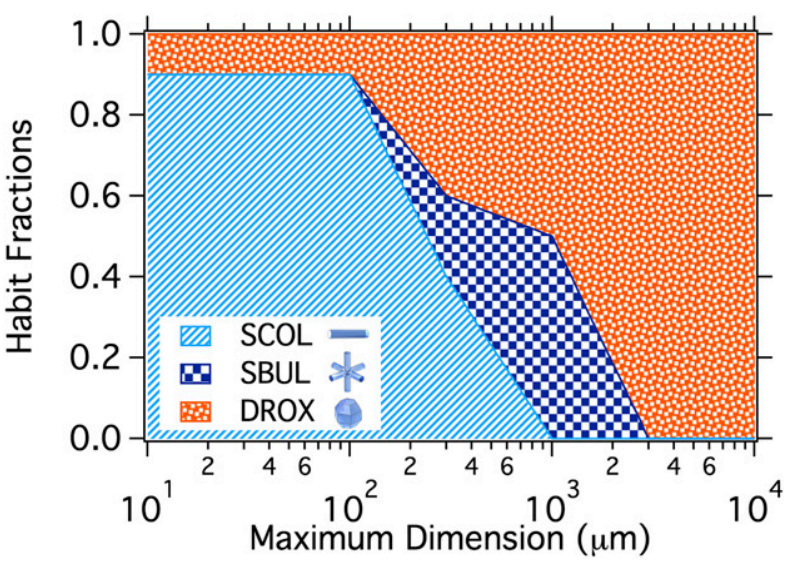

FIG. 1. Habit fraction diagram of the snow grain habit mixture (SGHM) model. The particle habits include the solid hexagonal column (SCOL), solid bullet rosette (SBUL), and droxtal (DROX).

or a single nonspherical shape over the entire snow particle size range (e.g., He et al. 2018c). The snow albedo is larger with nonspherical than spherical snow particles (Picard et al. 2009). Kikuchi et al. (2013) develop the "global classification of snow crystals" from snow in situ measurements reported in the literature from midlatitudes to polar regions. In general, the representative snow particle shape varies with the particle size. On the basis of several studies including direct snow particle in situ measurements, we develop the SGHM model shown in Fig. 1. Snow particle habit fractions vary linearly with respect to the logarithmic maximum dimension $(\log D)$ between particular size division points at $D=100,300,1000$, and $3000 \mu \mathrm{m}$.

In falling (i.e., fresh) snow in midlatitudes, needlelike dendrites are predominant (Kikuchi et al. 2013). From snow particle samples, newly accumulated snow has pristine needlelike and faceted particle shapes (A00; I18) or dendritic shapes (N01).

In the polar regions, fresh snow on the ground has a mixture of mostly column and platelike crystals with large aspect ratios and a smaller proportion of bullet cluster particles. The maximum dimension of columns and plates ranges from 2 to $1000 \mu \mathrm{m}$, and the sizes of bullet clusters may be around several thousand microns (Ohtake and Yogi 1979; Walden et al. 2003). However, Walden et al. (2003) found some samples in Antarctica where quasi-spherical snow particles predominate with a size range from a few to several tens of microns. Under a condition of low snowfall intensity, snowflakes are well grown and have a dendritic shape with needlelike branches (I18).

As we described in section 1, the snow metamorphosis process plays a dominant role in the variations of snow 
particle size and shape, after snow particles are accumulated on the surface (N01). In all regions, aged snow compared to fresh snow has significantly larger particle sizes and the former has faceted and granular particle shapes due to snow metamorphosis (I18).

From these reports, we assume snow particle habits to be mixtures of 1) SCOL with an aspect ratio of 0.25 (defined as the ratio of hexagonal column width $2 a$ to length $L$; i.e., $0<2 a / L \leq 1$ ), 2) SBUL (Yang et al. 2013), and 3) DROX (Yang et al. 2003; Zhang et al. 2004). The single-scattering properties of plate particles with arbitrary inverse aspect ratios (i.e., $0<L / 2 a \leq 1$ ) are similar to those of column-like particles with the corresponding aspect ratios (i.e., $2 a / L$ ). Depending on the aspect ratio, SCOL can be a surrogate of a plate particle, which we do not consider in the SGHM model. To mimic the observed irregularity and variability of snow particles on the surface, we assume that the particles are severely roughened using the degree of surface roughness $\left(\sigma^{2}=0.5\right)$ defined by Yang and Liou (1998). When the maximum dimension is less than $100 \mu \mathrm{m}$, we consider a mixture of snow particles that has $90 \%$ SCOL and $10 \%$ DROX, which mimics a semispherical granular particle. From 100 to $300 \mu \mathrm{m}$, the fraction of SCOL linearly decreases to $40 \%$, and the fraction of SBUL increases to $20 \%$. From 300 to $1000 \mu \mathrm{m}$, the fraction of SBUL increases to $50 \%$, while the fraction of SCOL decreases to $0 \%$. From 1000 to $3000 \mu \mathrm{m}$, the fraction of DROX increases to $100 \%$, which mimics the snow particle metamorphosis that produces granular crystals. Thus, this newly developed SGHM model is microphysically consistent with snow particle observations.

\section{b. Snow particle size distribution}

The snow particle metamorphosis process causes a significant increase in snow particle size. It is a challenge to specify the PSD of aged snow particles throughout this process. Therefore, we empirically estimate the snow PSD from in situ snow measurements. A00 found that both the snow PSD and particle shape change to larger and more compact particles in 4 days after a snowfall. N01 investigated snow particle metamorphism with laboratory experiments, demonstrating that needle-shaped snow particles became compact and granular particles, and the PSD is shifted to a larger size and with a broader PSD width, after exposure to solar radiation. I18 show accurate particle shapes of snow particles from natural accumulated snow and artificially generated snow including both new and aged snow samples, using an X-ray microtomography technique. Fresh snow particles have needlelike dendritic shapes, while aged snow particles have aggregated and granular shapes. Thus, these studies suggest that snow particle metamorphism causes the snow PSD to be broader with time.

To specify the PSD of snow particles, we first fit the PSDs to the gamma distribution using the 14 in situ measurement datasets from A00, N01, and I18. Those studies use several definitions of particle size bins, and we unify the size definitions by converting them to the maximum dimension $D$ and effective radius $r$. The appendix presents a detailed description of these snow in situ measurement datasets and the gamma fitting method. In each sample of snow particles for each size definition, the gamma distribution with respect to the maximum dimension is

$$
n(D)=N_{0}\left(\frac{D}{v}\right)^{\kappa-1} \exp \left(-\frac{D}{v}\right),
$$

where $\kappa$ and $v$ are the shape and scale parameters (Iwabuchi et al. 2012; Bi et al. 2014), and the gamma distribution with respect to the effective radius is

$$
n(r)=N_{0} r^{\left(1-3 v_{\mathrm{eff}}\right) / v_{\mathrm{eff}}} \exp \left(-\frac{r}{r_{\mathrm{eff}} v_{\mathrm{eff}}}\right),
$$

where $r_{\text {eff }}$ and $v_{\text {eff }}$ are the effective radius and variance of the snow PSDs (Hansen and Travis 1974).

For the 14 datasets in A00, N01, and I18, the left and right panels of Fig. 2 show best-fit gamma distribution parameters in Eqs. (5) and (6), respectively. In each panel, the solid line depicts the linear fit to the 14 sets of parameters, and each panel shows a linear relationship for the PSDs of the available samples with respect to either the maximum dimension or the effective radius. Note that these snow PSDs have a PSD shape that is quite different from those associated with ice clouds. Specifically, the values of the parameters $\kappa$ and $v$ for contrails (Iwabuchi et al. 2012) and cirrus clouds (Bi et al. 2014) deviate from those for snow particles on the surface. The snow PSD empirical fitting line indicates a broader PSD width than in contrails or cirrus clouds, because the solid line has a higher value (a larger shape parameter $\kappa$ ) than either of the fitted values for cloud ice particles. This difference is obviously caused by different microphysical processes to form microphysical structures of ice crystals in clouds and in accumulated snow. The ice cloud PSD is determined by diffusional growth, collision, and sublimation in ice clouds, while the accumulated snow PSD is determined by diffusional growth, and metamorphism associated with radiation, snowmelt, and refreezing. Note that a larger effective radius has a larger effective variance. 

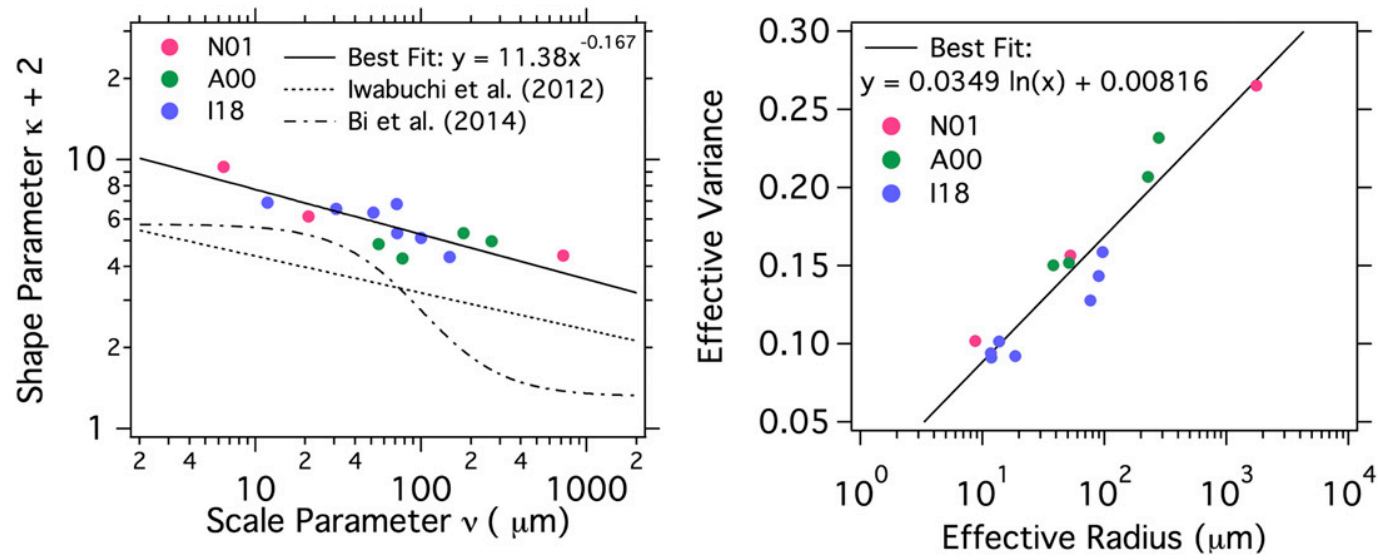

FIG. 2. Scatterplots of (left) shape and scale parameters for snow particle size distributions (PSD) with respect to the maximum dimension and (right) the effective radius and variance parameters for the snow PSD with respect to the effective radius. Solid lines depict the best fits of the parameters, and other lines depict previously developed PSD gamma distribution fits for contrails (dotted line; Iwabuchi et al. 2012) and cirrus clouds (dash-dotted line; Bi et al. 2014). Color plots indicate snow in situ measurements from N01 (pink), A00 (green), and I18 (purple).

\section{c. Internally mixed $B C$ in snow particles}

The BC mass fraction in snow particles varies by several orders of magnitude among locations from usually $<1.0 \mathrm{ng} \mathrm{g}^{-1}$ in Antarctica to sometimes $>1000 \mathrm{ng} \mathrm{g}^{-1}$ in a polluted region such as the Tibetan Plateau (Zhang et al. 2018). The snow albedo reduction is defined as the difference between the snow albedo for pure snow particles and that for BC internally mixed snow. Figure $3 \mathrm{a}$ shows snow albedo reductions associated with internally mixed $\mathrm{BC}$ over visible and near-infrared wavelengths calculated with an adding-doubling radiative transfer model, assuming single-scattering properties of droxtals and a single snow layer.

The snow albedo reduction largely depends on snow particle size, and also on the wavelength. Figure $3 \mathrm{~b}$ demonstrates the effects of snow particle shape on snow albedo reduction for the same volume-equivalent sphere radius. This size definition assures the same amount of BC mixed internally in snow particles with different shapes. The snow albedo reduction depends on snow particle shape, which is primarily due to the difference in the single-scattering properties.

\section{d. Bulk optical properties of the SGHM model}

The microphysically consistent SGHM model is consistent with sampled snow particles. Figure 4 shows the bulk optical properties of the SGHM model. The singlescattering coalbedo is mainly determined by the internally mixed BC amount at visible wavelengths and by snow particle size at near-infrared wavelengths.

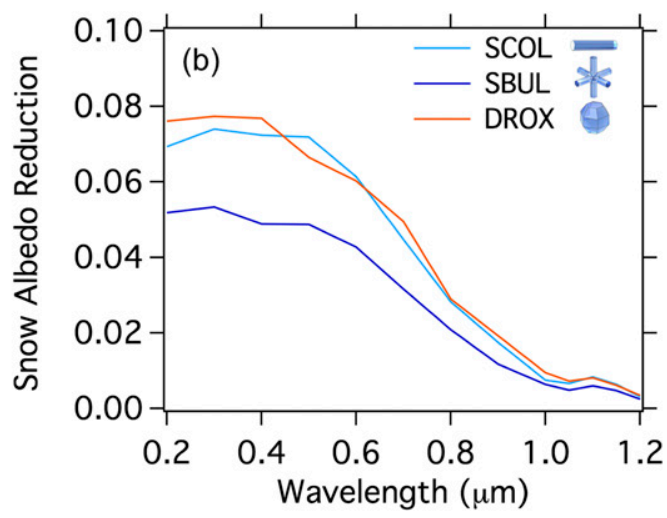

FIG. 3. Variation of snow albedo reductions associated with internal mixing of black carbon due to (a) snow particle size by assuming droxtal snow particles and (b) particle shape by assuming a volume-equivalent snow particle radius $R_{V}$ of $100 \mu \mathrm{m}$ and a BC mixing ratio of $1000 \mathrm{ng} \mathrm{g}^{-1}$. Each calculation is made for monodispersed particles (i.e., uniform particle size). 

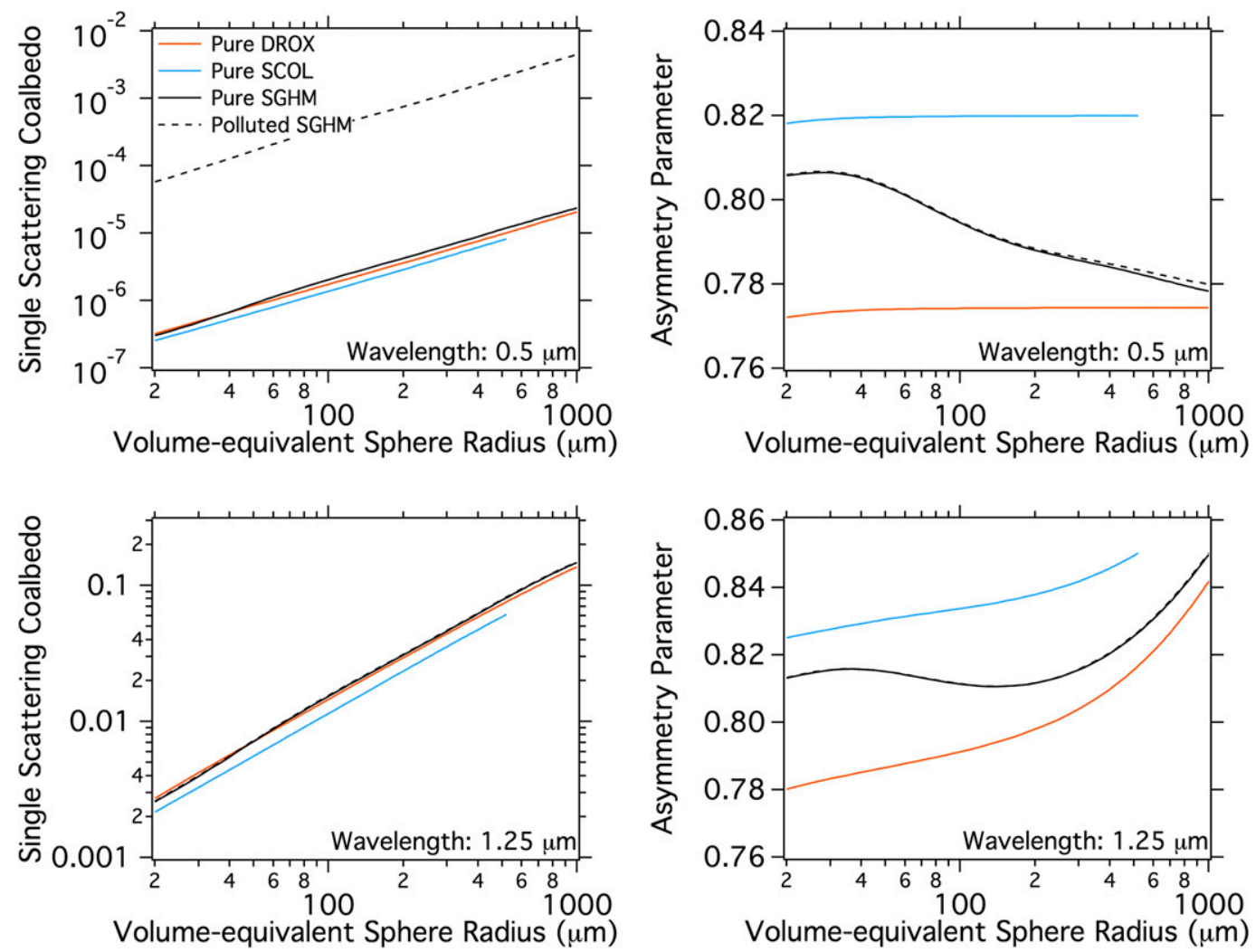

FIG. 4. The optical properties of the droxtal (DROX), solid hexagonal column (SCOL), and snow grain habit mixture (SGHM) model. (left) Single-scattering coalbedo and (right) asymmetry parameter for (top) a visible wavelength $(0.5 \mu \mathrm{m})$ and (bottom) a near-infrared wavelength $(1.25 \mu \mathrm{m})$.

The particle shape (with the same particle volume) has an insignificant impact on the single-scattering coalbedo. In other words, the impacts of particle shape on the singlescattering coalbedo are not negligible under the condition with the same snow particle effective radius.

I18 demonstrates that the asymmetry parameter of snow particles decreases with increasing volume-equivalent spherical radius at both wavelengths 0.532 and $1.242 \mu \mathrm{m}$. The SGHM computes similar changes in the asymmetry parameter at a visible wavelength $(\lambda=$ $0.5 \mu \mathrm{m})$. However, single snow particle shape assumptions (i.e., all DROX or all SCOL) do not lead to a similar decrease. Therefore, the mixture of multiple snow particle shapes is necessary to optimally simulate the bulk optical properties of natural snow particles. For a near-infrared wavelength $(\lambda=1.25 \mu \mathrm{m})$, the SGHM does not compute a similar decrease with a volume-equivalent sphere radius larger than $200 \mu \mathrm{m}$. This implies that the particle shape assumed in the corresponding size domain (i.e., mostly DROX) may not be appropriate, or the near-field interaction among snow particles may be important for the singlescattering properties in densely packed snow. In these aspects, further investigations are needed and left for future work.

\section{Rigorous snow albedo simulations}

This section first compares the spectral snow albedo model based on the SGHM with an existing snow albedo model and direct snow albedo observations, and then presents sensitivity studies.

\section{a. Comparisons with reliable simulations and observations}

To evaluate the performance of the spectral snow albedo model based on the SGHM, we compare the spectral snow albedo simulations with those from the single-layer SNICAR model (Flanner et al. 2007) and observations in Antarctica (Grenfell et al. 1994). The SNICAR (http://snow.engin.umich.edu/info.html) model computes snow albedo based on the two-stream approximation and a spherical particle assumption. Figure 5 compares spectral snow albedo for a $\mathrm{BC}$ mass fraction of $0 \mathrm{ngg}^{-1}$ (pure snow) and an SZA of $50^{\circ}$. The SNICAR calculation assumes a snow particle effective radius of 


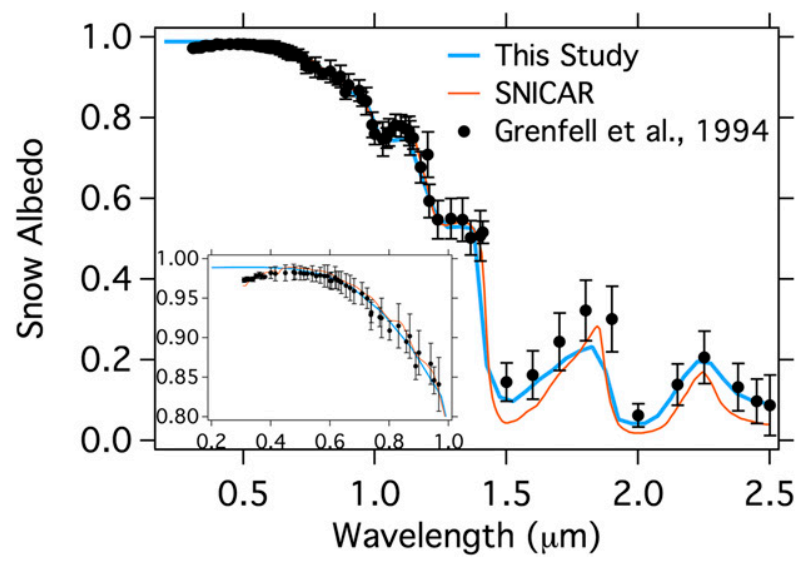

FIG. 5. Comparison of the two-layer-based spectral snow albedo simulations in this study with the SNICAR model (Flanner et al. 2007) and observations in Antarctica (Grenfell et al. 1994). The inset is a magnification of the top-left portion of the main panel.

$80 \mu \mathrm{m}$, which achieves the best fit to the Grenfell et al. (1994) observations based on a single-layer assumption. Grenfell et al. (1994) provide particle size statistics for several snow depth bins from snow in situ measurements, indicating that average snow particle radius just below the surface snow is $52 \mu \mathrm{m}$, and the size sharply increases toward a snow depth of $10-100 \mathrm{~mm}$, ranging from 122 to $191 \mu \mathrm{m}$ [see Table 4 in Grenfell et al. (1994) for more details]. Based on their datasets, our model assumes SWE in the top layer to be $0.05 \mathrm{~mm}$, and the top and second snow layer have effective particle radii of 52 and $160 \mu \mathrm{m}$, respectively. The results show that the present snow albedo calculation based on SGHM is consistent with both the single-layer SNICAR model and observations in a spectral region from the visible to $1.4 \mu \mathrm{m}$, and outperforms SNICAR with $\lambda>2.0 \mu \mathrm{m}$ due to taking account of the two-layer snow surface and variation of snow particle habits in this study. These are promising results for the SGHM because spectral snow albedo simulations are consistent with observed snow particle size and snow-layer characteristics. Note that underestimated snow albedo by the SGHM compared to observations for $\lambda=$ $1.5-1.9 \mu \mathrm{m}$ may come from uncertainty in the refractive index of ice compiled by Warren and Brandt (2008), which is further discussed in Carmagnola et al. (2013).

\section{b. Sensitivity of snow characteristics to snow albedo}

Figure 6 shows the sensitivity of the snow albedo to snow particle effective radius and internally mixed BC mass fractions, assuming a single snow layer and the SGHM bulk optical properties. As demonstrated previously (e.g., A00; Flanner et al. 2007; He et al. 2018c), a larger snow particle effective radius reduces the snow albedo in the infrared spectral region, while $\mathrm{BC}$ internal mixing reduces the snow albedo in the visible region. The magnitude of snow albedo reduction due to BC internal mixing becomes larger with a larger snow particle effective radius.

Figure 7 demonstrates the impact of SWE in the top snow layer on snow albedo under various two-layer snow conditions. The snow particle effective radius is assumed to be $30 \mu \mathrm{m}$ for the top layer and $500 \mu \mathrm{m}$ for the second layer, and the second layer is thick enough to be opaque. In the spectral region of $0.2-0.8 \mu \mathrm{m}$, the snow albedo does not change with SWE in the top layer of pure snow due to weak ice absorption, but increases as the top-layer SWE increases with polluted snow
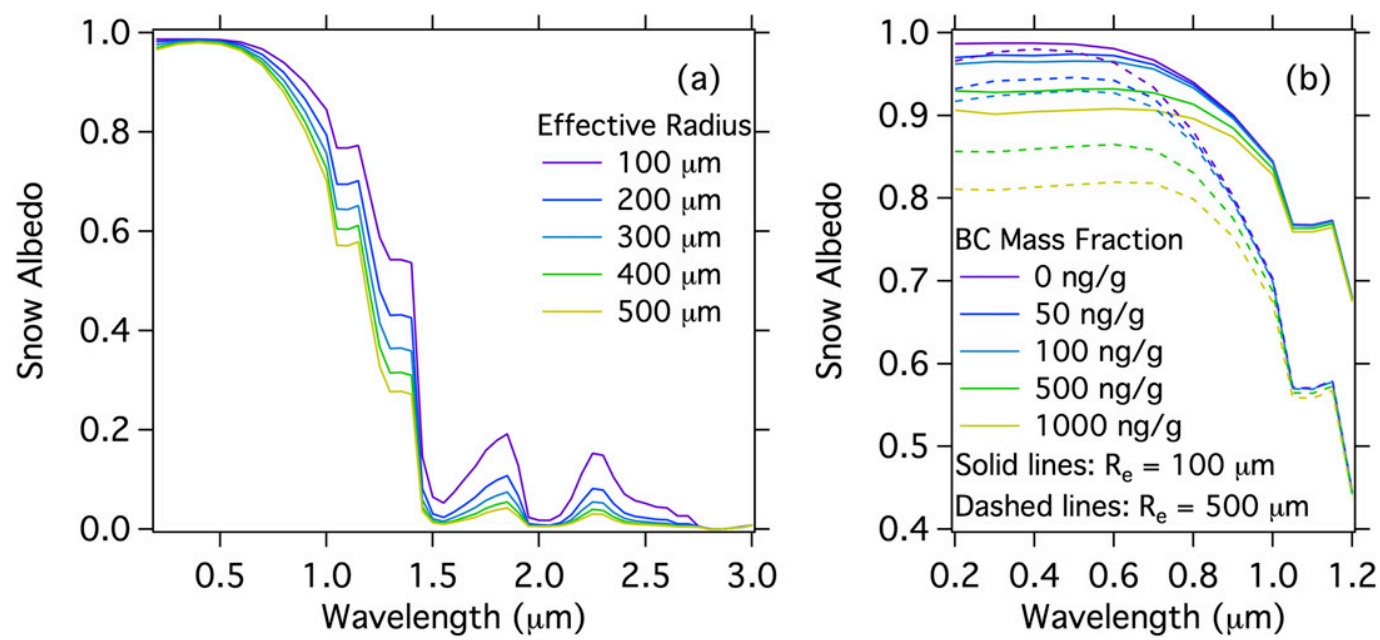

FIG. 6. Snow albedo variations associated with (a) snow particle size and (b) BC mass fraction. All calculations assume a single opaque snow layer and an SZA of $45^{\circ}$. 

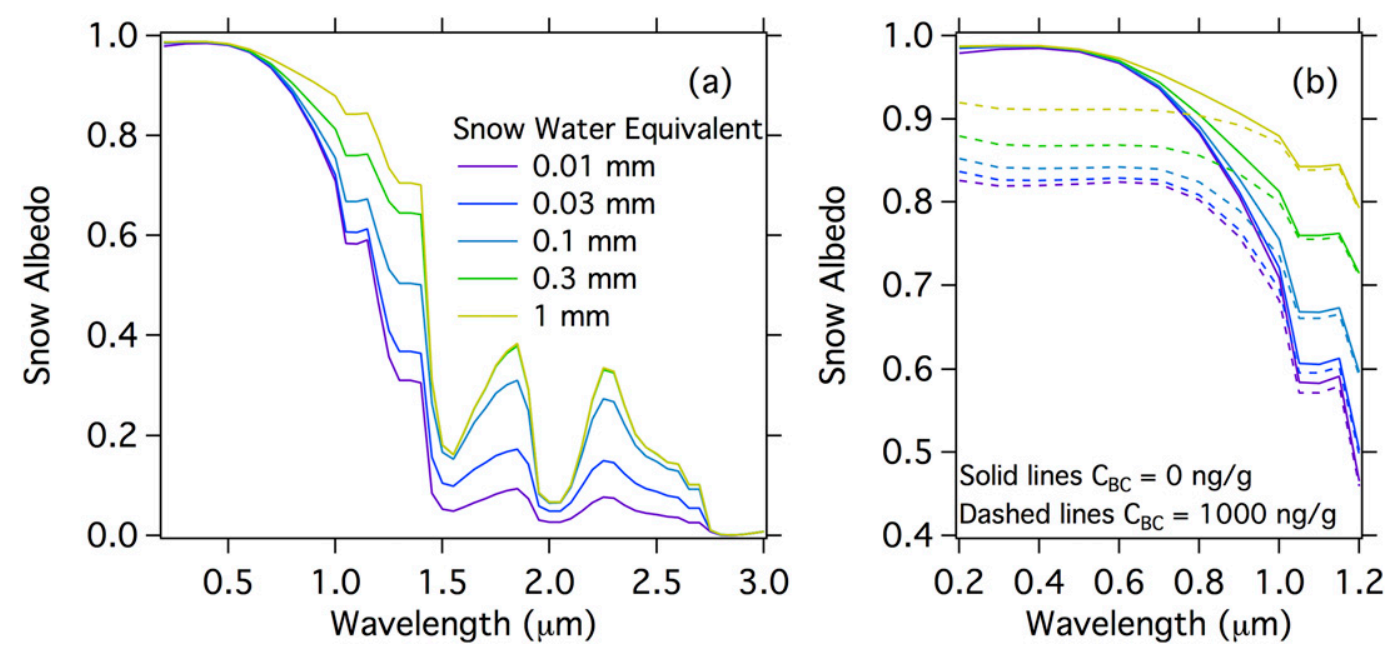

FIG. 7. (a) Pure snow albedo variations associated with SWE by assuming a snow particle effective radius of $30 \mu \mathrm{m}$ for the top snow layer and $500 \mu \mathrm{m}$ for the second snow layer. The second layer is thick enough to be opaque. (b) As in (a), but comparing pure snow (solid lines) and snow with $1000 \mathrm{ng} \mathrm{g}^{-1}$ of BC (dashed lines). All calculations assume a solar zenith angle of $45^{\circ}$.

(Fig. 7b). In the spectral region of $0.8-1.5 \mu \mathrm{m}$, solar radiation penetrates into the top snow layer, and even a small SWE variation plays an important role in snow albedo when the top-layer SWE $<1 \mathrm{~mm}$. Nolin and Dozier (2000) investigate penetration depth of solar light into a single snow layer. At wavelength $\lambda=$ $1.03 \mu \mathrm{m}$, the penetration depth (defined by $1 / e$ of solar intensity) is $1.2 \mathrm{~mm}$ of SWE for an effective radius of $50 \mu \mathrm{m}$, and the penetration depth increases with increasing snow particle effective radius. Aoki et al. (2011) similarly shows that solar radiation penetration depth increases with larger snow particle effective radius, and decreases with increasing snow impurities. In the spectral region of $\lambda>1.5 \mu \mathrm{m}$, solar radiation does not penetrate far into the top snow layer, and the snow albedo is almost identical to the albedo of the top layer when top-layer SWE $>0.1-0.3 \mathrm{~mm}$. A typical snow cover has a vertically inhomogeneous structure with smaller snow particle effective radii in the upper layers. These results show that a two-layer snow-cover model (fresh and aged snow) is sufficient to simulate reliable spectral snow albedo at both visible and infrared wavelengths. This finding is consistent with the result of Dang et al. (2017).

Figure 8 illustrates snow albedo variations associated with SZA. In the infrared, the sensitivity of snow albedo
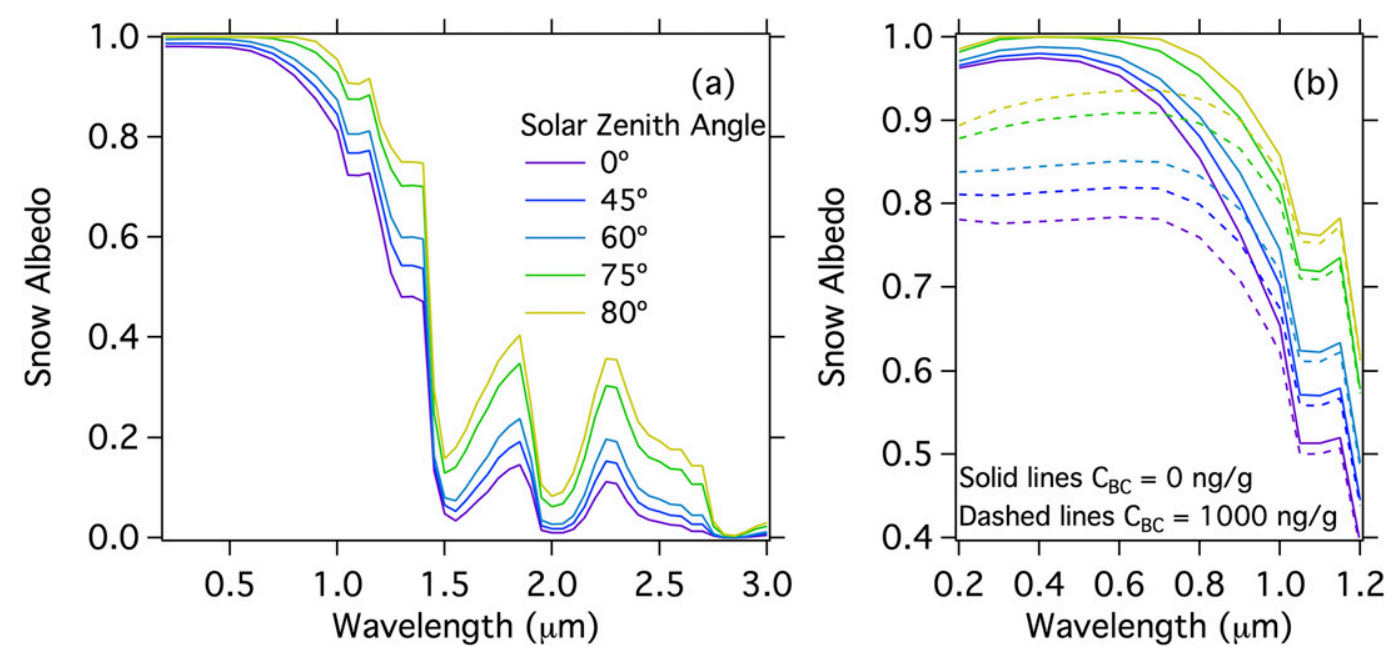

FIG. 8. (a) Pure snow albedo variations associated with SZAs for a single snow layer with a snow particle effective

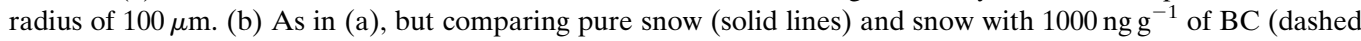
lines). In both cases, the snow particle effective radius is $500 \mu \mathrm{m}$. 


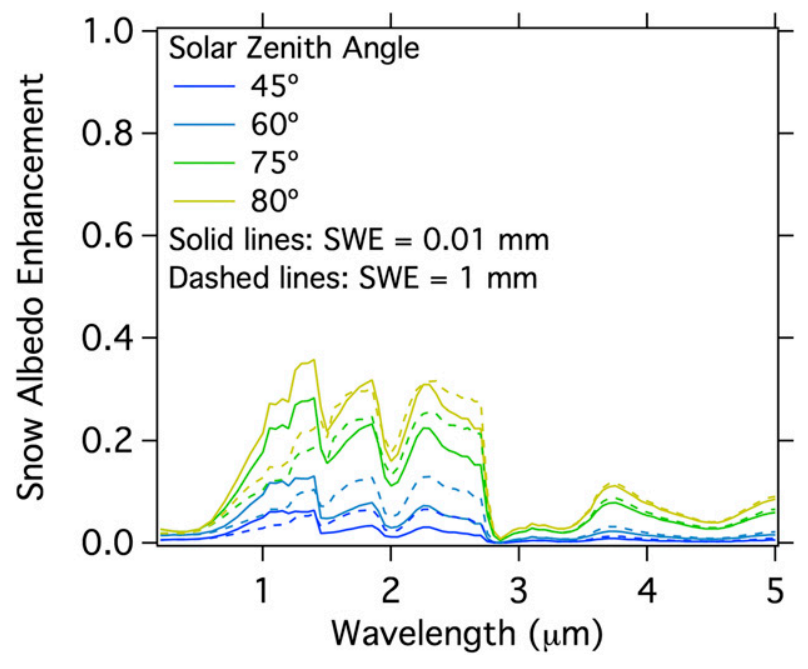

FIG. 9. Snow albedo enhancement associated with SZAs for different SWE values in the top snow layer. All calculations assume a snow particle effective radius of $30 \mu \mathrm{m}$ for the top snow layer and $500 \mu \mathrm{m}$ for the second snow layer. The second snow layer is thick enough to be opaque.

to SZA is similar to the sensitivity to snow particle effective radius (Marshall 1989), but the former sensitivity is stronger at visible wavelengths. In this spectral region, a large SZA corresponds to a large snow albedo due to increased contribution by the side scattering of snow particles to the reflected solar radiation. Moreover, $\mathrm{BC}$ internal mixing enhances the snow albedo in the visible spectral region when SZA is large.

Figure 9 shows the snow albedo enhancement under two-layer snow conditions. Here snow albedo enhancement is defined as the snow albedo minus that with an SZA of $0^{\circ}$. The snow particle effective radius is $30 \mu \mathrm{m}$ for the top layer and $500 \mu \mathrm{m}$ for the second layer. The results show that the snow albedo enhancement is almost identical for the cases with top-layer SWEs of 0.01 and $1.0 \mathrm{~mm}$ in the infrared spectral region, and has a similar magnitude at visible to near-infrared wavelengths. This implies that snow particle optical properties in a thin top layer dominate the snow albedo enhancement when SZA is large.

\section{Snow albedo parameterizations}

This section describes mathematical formulas for single- and two-layer snow albedo parameterizations, and presents the evaluation of these parameterizations.

\section{a. A single-layer snow albedo parameterization}

This study first develops a snow albedo parameterization for a single snow layer in the six LaRC-FL RTM bands in the shortwave spectral region. Each parameterization is
TABLE 2. Size relationships ( $\mu \mathrm{m})$ among snow particle effective radius $R_{e}$, volume-equivalent sphere radius $R_{V}$, and projectedarea-equivalent sphere radius $R_{A}$ based on the SGHM model.

\begin{tabular}{rrr}
\hline$R_{e}$ & $R_{V}$ & \multicolumn{1}{c}{$R_{A}$} \\
\hline 50 & 46.10 & 44.27 \\
100 & 84.05 & 77.06 \\
150 & 122.55 & 110.77 \\
200 & 161.50 & 145.13 \\
250 & 200.02 & 178.91 \\
300 & 237.58 & 211.42 \\
350 & 273.58 & 242.26 \\
400 & 308.79 & 271.31 \\
450 & 342.60 & 298.93 \\
500 & 375.45 & 325.34 \\
600 & 439.03 & 375.55 \\
700 & 500.83 & 423.62 \\
800 & 561.66 & 470.61 \\
900 & 622.10 & 517.21 \\
1000 & 682.52 & 563.86 \\
\hline
\end{tabular}

based on a nonlinear regression fit to rigorously calculated snow albedo datasets using a large number of cases. The variables in the parameterization include snow particle effective radius $R_{e}(30-1000 \mu \mathrm{m})$, internally mixed BC mass fraction $C_{\mathrm{BC}}\left(0-1000 \mathrm{ng} \mathrm{g}^{-1}\right)$, and the cosine of SZA $\mu_{0}(0.2-1)$. The optical thickness of the snow layer is assumed to be 960 (i.e., semi-infinite). Some land-snow models use a different definition of snow particle size. Table 2 lists the relationships between $R_{e}$ and those based on two other size definitions $\left(R_{V}\right.$ and $\left.R_{A}\right)$. Conversion of $R_{V}$ or $R_{A}$ to the equivalent $R_{e}$ value may be necessary for implementing this proposed parameterization within the GCM framework. The snow albedo is nonlinear with respect to snow particle effective radius (e.g., Dang et al. 2015). Thus, the pure snow albedo $\alpha_{s, \text { pure }}$ is parameterized in the form

$$
\alpha_{s, \text { pure }}=p_{s, 0}+p_{s, 1} \log _{10} R_{n}+p_{s, 2}\left(\log _{10} R_{n}\right)^{2},
$$

where $p_{s, i}$ is a coefficient (see Table 3 ), $R_{n}$ is defined as $R_{e} / R_{0}$, and $R_{0}$ is assumed to be $30 \mu \mathrm{m}$. The first subscript $s$ means a single snow layer, which could represent either fresh or aged snow. This parameterization provides a fairly accurate snow albedo, and the performance is well documented in the literature (Dang et al. 2015).

The snow albedo reduction associated with $C_{\mathrm{BC}}$ depends on the snow particle effective radius as shown in Fig. 8. Parameterization of snow albedo reduction is based on the following empirical equation, with coefficients $q_{s, i}$ similar to He et al. (2018c):

$$
\Delta \alpha_{s}=q_{s, 0} C_{\mathrm{BC}}^{k_{n}},
$$

where 
TABLE 3. Coefficients of the single-layer snow albedo parameterization for the six broad bands of the NASA Langley Research Center's modified Fu-Liou broadband radiative transfer model.

\begin{tabular}{|c|c|c|c|c|c|c|}
\hline Coef & Band 1 & Band 2 & Band 3 & Band 4 & Band 5 & Band 6 \\
\hline$\lambda(\mu \mathrm{m})$ & $0.2-0.7$ & $0.7-1.3$ & $1.3-1.9$ & $1.9-2.5$ & $2.5-3.5$ & $3.5-4.0$ \\
\hline$p_{s, 0}$ & $9.74090 \times 10^{-1}$ & $8.87889 \times 10^{-1}$ & $3.09339 \times 10^{-1}$ & $1.26979 \times 10^{-1}$ & $1.43595 \times 10^{-2}$ & $1.06946 \times 10^{-2}$ \\
\hline$p_{s, 1}$ & $-8.79490 \times 10^{-3}$ & $-9.05519 \times 10^{-2}$ & $-2.83309 \times 10^{-1}$ & $-1.77534 \times 10^{-1}$ & $-1.07286 \times 10^{-2}$ & $-1.02771 \times 10^{-2}$ \\
\hline$p_{s, 2}$ & $-1.69630 \times 10^{-2}$ & $-5.55851 \times 10^{-2}$ & $7.06140 \times 10^{-2}$ & $6.66492 \times 10^{-2}$ & $4.34945 \times 10^{-3}$ & $4.09057 \times 10^{-3}$ \\
\hline$q_{s, 0}$ & $2.83408 \times 10^{-3}$ & $2.39082 \times 10^{-4}$ & - & - & - & - \\
\hline$q_{s, 1}$ & $4.36222 \times 10^{-1}$ & $6.65330 \times 10^{-1}$ & - & - & - & - \\
\hline$q_{s, 2}$ & $1.15358 \times 10^{-1}$ & $6.75072 \times 10^{-2}$ & - & - & - & - \\
\hline$s_{s, 0}$ & $7.12707 \times 10^{-1}$ & $1.02129 \times 10^{0}$ & $1.36320 \times 10^{0}$ & $1.71768 \times 10^{0}$ & $1.14413 \times 10^{0}$ & $1.81024 \times 10^{0}$ \\
\hline$s_{s, 1}$ & $-6.79194 \times 10^{-1}$ & $-2.79270 \times 10^{-1}$ & $4.10501 \times 10^{-2}$ & $-6.31257 \times 10^{-2}$ & $2.58422 \times 10^{-3}$ & $-4.95900 \times 10^{-2}$ \\
\hline$s_{s, 2}$ & $7.33010 \times 10^{-1}$ & $4.03019 \times 10^{-1}$ & $1.20594 \times 10^{0}$ & $2.13634 \times 10^{0}$ & $2.83219 \times 10^{-1}$ & $1.45400 \times 10^{+1}$ \\
\hline$s_{s, 3}$ & $-7.57024 \times 10^{-1}$ & $-7.54092 \times 10^{-1}$ & $9.30324 \times 10^{-1}$ & $5.36167 \times 10^{-1}$ & $5.34267 \times 10^{-1}$ & $9.52150 \times 10^{-1}$ \\
\hline
\end{tabular}

$$
k_{n}=q_{s, 1} R_{n}^{q_{s, 2}}
$$

From Eqs. (8) and (9), we obtain a representative snow albedo $\alpha_{s, 0}$ by

$$
\alpha_{s, 0}=\alpha_{s, \text { pure }}-\Delta \alpha_{s}
$$

Gardner and Sharp (2010) consider SZA effects on snow albedo parameterization with SZA greater than $60^{\circ}$. However, the nonlinear dependence of snow albedo enhancement on both snow particle effective radius and BC internal mixing does not allow a simple parameterization (Figs. 8 and 9). Therefore, we empirically fit the snow albedo enhancement $\alpha_{s, \text { enh }}$ using coefficients $s_{s, i}$, the cosine of SZA $\mu_{0}$, and the following equation:

$$
\alpha_{s, \mathrm{enh}}=l_{n}\left(\frac{1-\mu_{0}}{1+\mu_{0}}\right)^{s_{s, 0}}
$$

where

$$
l_{n}=s_{s, 1}+s_{s, 2} \alpha_{s, 0}^{s_{s, 3}} .
$$

We obtain the single-layer snow albedo as a function of snow particle effective radius, BC mass fraction, and SZA in the form

$$
\alpha_{s}=\alpha_{s, 0}+\alpha_{s, \mathrm{enh}}
$$

Overall, this single-layer snow albedo parameterization considers nonlinear variations associated with snow particle effective radius, BC internal mixing in snow particles, and SZA.

Figure 10 shows the validation of the single-layer snow albedo parameterization in the six LaRC-FL RTM bands in comparison with rigorous simulations based on radiative transfer calculations described in section 4, for various snow and SZA cases such as snow particle effective radii of $100-500 \mu \mathrm{m}, \mathrm{BC}$ mass fractions of $0-1000 \mathrm{ng} \mathrm{g}^{-1}$, and cosines of SZA of 0.2-1. In Fig. 10, each parameterization represents the band-mean snow albedo with a correlation coefficient greater than 0.98 . The comparisons also show that snow albedo changes associated with SZAs are important in visible to nearinfrared bands (i.e., 1 and 2) and even play a major role in snow albedo in bands 3-6.

Figure 11 compares snow albedo parameterizations between this study and $\mathrm{He}$ et al. (2018c), which is a function of snow particle effective radius and $\mathrm{BC}$ internal mixing fraction assuming spherical and Koch snowflake particle models. Because the $\mathrm{He}$ et al. parameterization uses a constant SZA of $49.5^{\circ}$, this figure does not consider SZA dependence. The parameterization in this study more closely resembles the Koch snowflake parameterization than the spherical parameterization due to similar particle asphericity in the SGHM and Koch snowflake models. Both $\mathrm{He}$ et al. parameterizations in Fig. 11a tend to underestimate snow albedo due to differences in snow particle shape and in the internally mixed BC PSD. The He et al. parameterization is based on a monodispersed (i.e., a uniform particle size) BC PSD with a radius of $0.1 \mu \mathrm{m}$, while our study assumes an effective radius and variance of $0.1 \mu \mathrm{m}$ and 0.1 , providing weaker absorption based on the bulk optical properties of snow particles (He et al. 2018b). Therefore, our parameterization has a higher snow albedo than that computed by $\mathrm{He}$ et al. (2018c). In bands 3-6 (Fig. 11b), the bias is basically small and mainly due to particle shape differences and uncertainty in nonlinear regression fits.

\section{b. A two-layer snow albedo parameterization}

We expand the parameterization to a two-layer case. The subscript $t$ in following equations indicates a two-layer parameterization. The two-layer snow albedo parameterization is similar to the single-layer parameterization based on Eqs. (7)-(13), but coefficients 

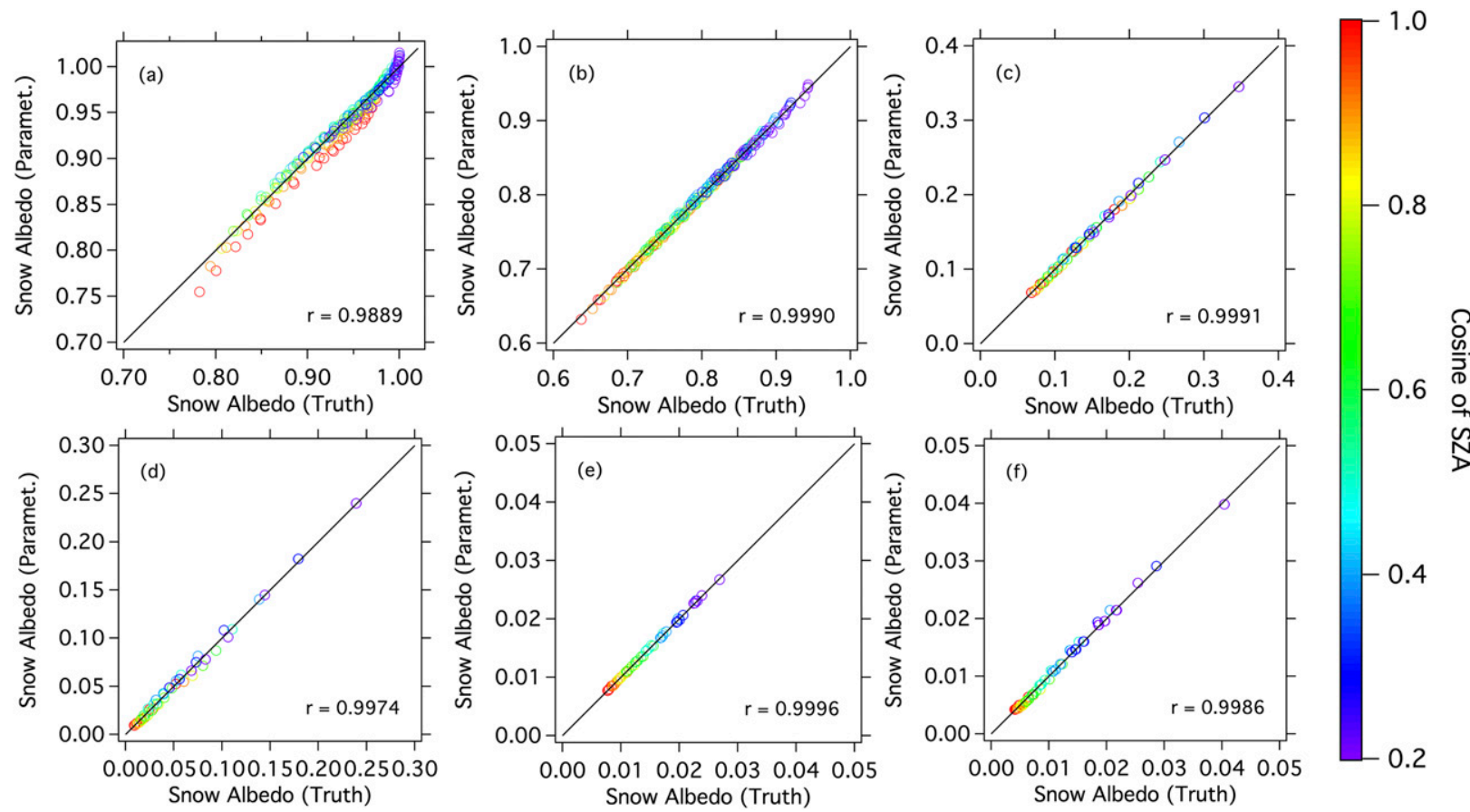

FIG. 10. Comparisons of snow albedo for (a) band 1 to (f) band 6 of the NASA Langley Research Center's modified Fu-Liou broadband radiative transfer model, between rigorous snow albedo simulations (referred to as "Truth") and the single-layer snow albedo parameterization (referred to as "Paramet."). The color scale denotes the cosine of SZA associated with each data point.

$p_{s, i}, q_{s, i}$, and $s_{s, i}$ are replaced by counterparts $p_{t, i}, q_{t, i}$, and $s_{t, i}$ (Table 4). The variables in the parameterization include snow particle effective radii for the top $R_{e 1}(30-500 \mu \mathrm{m})$ and second layers $R_{e 2}(100-1000 \mu \mathrm{m})$, SWE in the top layer $w(0.01-1 \mathrm{~mm}), C_{\mathrm{BC}}$, and $\mu_{0}$. In addition, two modifications take into account the bulk optical properties of snow in each layer. First, we replace the single-layer $R_{n}$ with

$$
R_{n}=\left\{1-e^{-t_{0}\left[w /\left(R_{e 1} \mu_{0}\right)\right]}\right\}\left(\frac{R_{e 1}}{R_{0}}\right)+e^{-t_{0}\left[w /\left(R_{e 1} \mu_{0}\right)\right]}\left(\frac{R_{e 2}}{R_{0}}\right),
$$
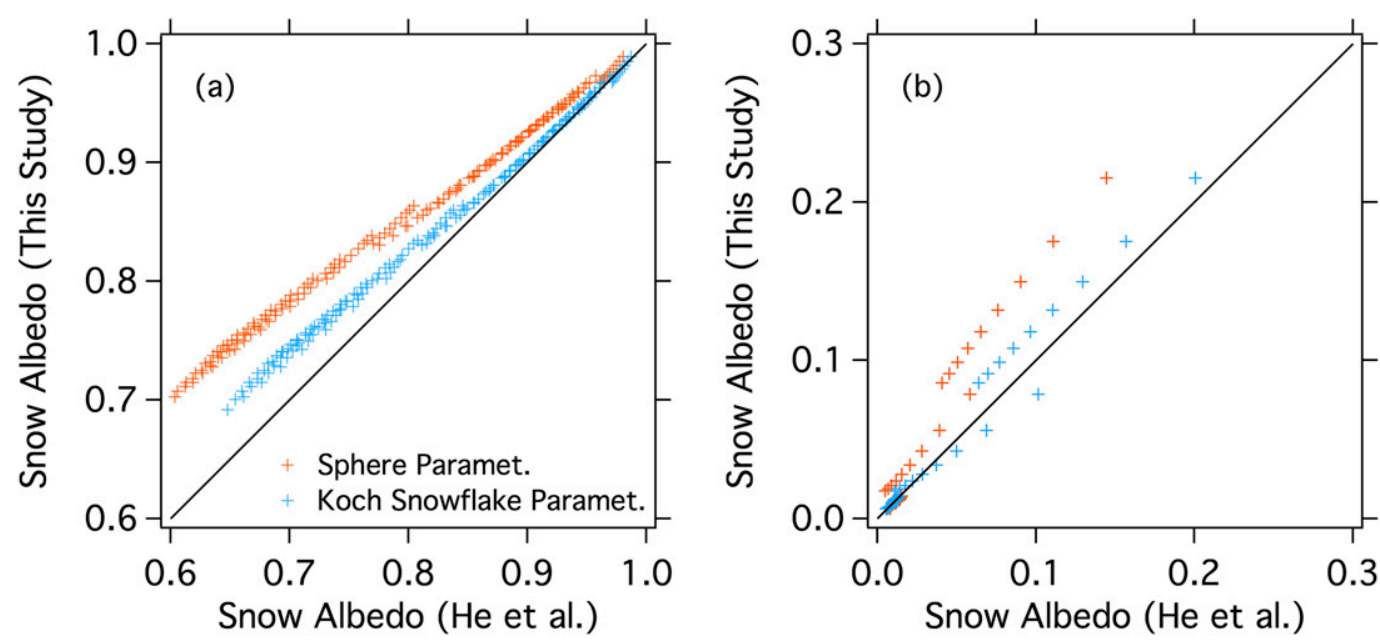

FIG. 11. Comparisons of band-average snow albedo based on single-layer snow albedo parameterizations between this study and He et al. (2018c) for (a) bands 1 and 2 and (b) bands 3-6 of the NASA Langley Research Center's modified Fu-Liou broadband radiative transfer model. Orange and blue colors show spherical and Koch snowflake shape-based parameterizations from He et al. (2018c). 
TABLE 4. Coefficients of the two-layer snow albedo parameterization for the six broad bands of the NASA Langley Research Center's modified Fu-Liou broadband radiative transfer model.

\begin{tabular}{|c|c|c|c|c|c|c|}
\hline Coef & Band 1 & Band 2 & Band 3 & Band 4 & Band 5 & Band 6 \\
\hline$\lambda(\mu \mathrm{m})$ & $0.2-0.7$ & $0.7-1.3$ & $1.3-1.9$ & $1.9-2.5$ & $2.5-3.5$ & $3.5-4.0$ \\
\hline$p_{t, 0}$ & $9.66798 \times 10^{-1}$ & $8.47233 \times 10^{-1}$ & $3.17371 \times 10^{-1}$ & $1.68931 \times 10^{-1}$ & $1.67440 \times 10^{-2}$ & $2.09481 \times 10^{-2}$ \\
\hline$p_{t, 1}$ & $1.46398 \times 10^{-2}$ & $-3.69101 \times 10^{-2}$ & $-2.80161 \times 10^{-1}$ & $-2.32944 \times 10^{-1}$ & $-1.46426 \times 10^{-2}$ & $-2.93387 \times 10^{-2}$ \\
\hline$p_{t, 2}$ & $-2.06975 \times 10^{-2}$ & $-6.60701 \times 10^{-2}$ & $6.44811 \times 10^{-2}$ & $8.15570 \times 10^{-2}$ & $6.43931 \times 10^{-3}$ & $1.27112 \times 10^{-2}$ \\
\hline$q_{t, 0}$ & $2.84275 \times 10^{-3}$ & $2.22877 \times 10^{-4}$ & - & - & - & - \\
\hline$q_{t, 1}$ & $4.40491 \times 10^{-1}$ & $6.46529 \times 10^{-1}$ & - & - & - & - \\
\hline$q_{t, 2}$ & $9.61721 \times 10^{-2}$ & $6.69362 \times 10^{-2}$ & - & - & - & - \\
\hline$s_{t, 0}$ & $1.18422 \times 10^{0}$ & $1.05779 \times 10^{0}$ & $1.43539 \times 10^{0}$ & $1.67788 \times 10^{0}$ & $1.39309 \times 10^{0}$ & $1.89728 \times 10^{0}$ \\
\hline$s_{t, 1}$ & $-1.95762 \times 10^{0}$ & $-6.97743 \times 10^{-1}$ & $3.48784 \times 10^{-2}$ & $2.38503 \times 10^{-2}$ & $-4.05257 \times 10^{-2}$ & $1.36049 \times 10^{-2}$ \\
\hline$s_{t, 2}$ & $2.02800 \times 10^{0}$ & $8.81507 \times 10^{-1}$ & $8.77138 \times 10^{-1}$ & $1.88333 \times 10^{0}$ & $4.38328 \times 10^{-1}$ & $1.00362 \times 10^{4}$ \\
\hline$s_{t, 3}$ & $-2.87068 \times 10^{-1}$ & $-1.73958 \times 10^{-1}$ & $8.35008 \times 10^{-1}$ & $6.64771 \times 10^{-1}$ & $3.93435 \times 10^{-1}$ & $2.42350 \times 10^{0}$ \\
\hline$t_{t, 0}$ & $8.29327 \times 10^{1}$ & $1.42319 \times 10^{2}$ & $7.21956 \times 10^{2}$ & $8.92034 \times 10^{2}$ & $2.05585 \times 10^{3}$ & $2.39200 \times 10^{3}$ \\
\hline
\end{tabular}

where $t_{0}$ is a coefficient, $R_{e 1}$ and $R_{e 2}$ are the snow particle effective radii for the top and second snow layers, and $w$ is SWE in the top layer. The second layer is opaque as in the previously discussed cases. The coefficient $t_{0}$ roughly represents absorptivity of the bulk snow optical properties in a given band, and therefore a larger $t_{0}$ value indicates a larger contribution of the snow optical properties of the top layer to the band snow albedo. Second, to calculate snow albedo enhancement associated with SZA, we replace Eq. (11) with

$$
\alpha_{t, \mathrm{enh}}=l_{n}\left(\frac{1-\mu_{0}}{1+\mu_{0}}\right)^{s_{t, 0}}
$$

where

$$
l_{n}=s_{t, 1}+s_{t, 2} \alpha_{s, 0}^{s_{t, 3}}
$$

Because the snow albedo enhancement associated with SZA is most sensitive to the optical properties of the top snow layer, we use the same representative snow albedo $\alpha_{s, 0}$ [Eq. (10)] from the single-layer snow albedo parameterization for the top-layer optical properties (i.e., $R_{e 1}$ and $C_{\mathrm{BC}}$ ). As in the single-layer snow albedo parameterization, the coefficients for the two-layer snow albedo parameterization are determined through nonlinear regression fits based on rigorous snow albedo calculations with various snow particle characteristics, SZA conditions, and toplayer SWEs.

Figure 12 compares snow albedo from the two-layer snow albedo parameterization with the rigorous calculations. Overall, the two-layer snow albedo parameterization agrees with rigorous calculations with a correlation coefficient of 0.9897 .

It is also of interest to estimate the snow albedo bias when the two-layer snow structure is ignored. Figure 13 shows the snow albedo differences between the single- and two-layer snow albedo parameterizations. We assume that the two-layer snow albedo parameterization provides an unbiased snow albedo, while the single-layer snow albedo parameterization provides two values of snow albedo models: one is based on snow optical properties from the top layer (i.e., without considering the second layer), and the other is based on those in the second snow layer (i.e., without considering the top layer). The snow accumulation depth $d_{\text {snow }}$ of the top layer is assumed to be $2 \mathrm{~cm}$ with a typical fresh-snow density $\left(\rho_{\text {snow }}=0.11 \mathrm{~g} \mathrm{~cm}^{-3}\right)$, which corresponds to $\mathrm{SWE}$ of $2.2 \mathrm{~mm}$. Figures $13 \mathrm{a}$ and $13 \mathrm{c}$ indicate that

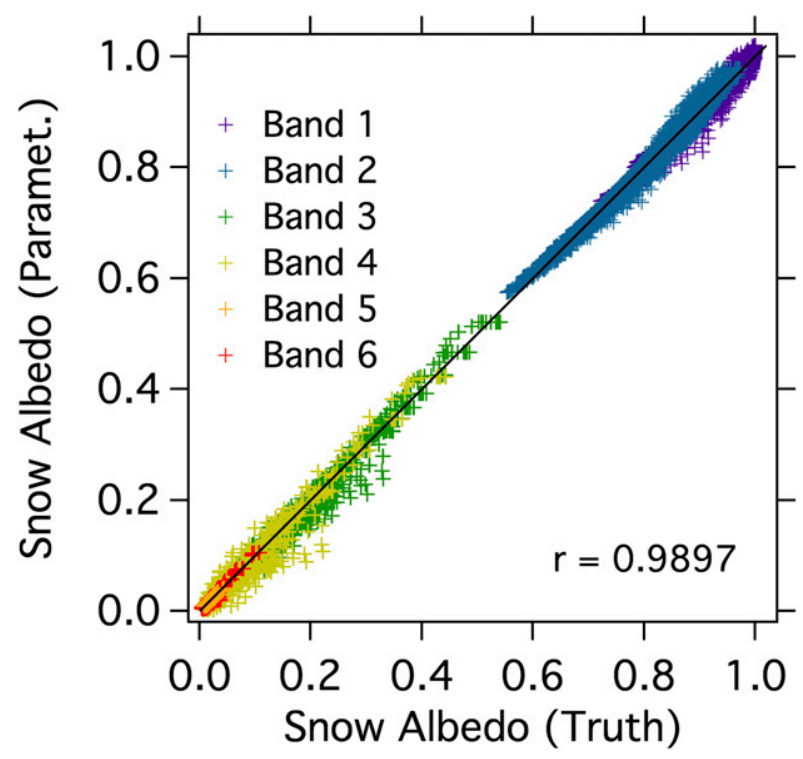

FIG. 12. Comparisons of band snow albedo for a two-layer snow surface between rigorous snow albedo simulations (referred to as "Truth") and the two-layer snow albedo parameterization (referred to as "Paramet."). The color of each data point denotes the band number of the NASA Langley Research Center's modified $\mathrm{Fu}-$ Liou broadband radiative transfer model. 

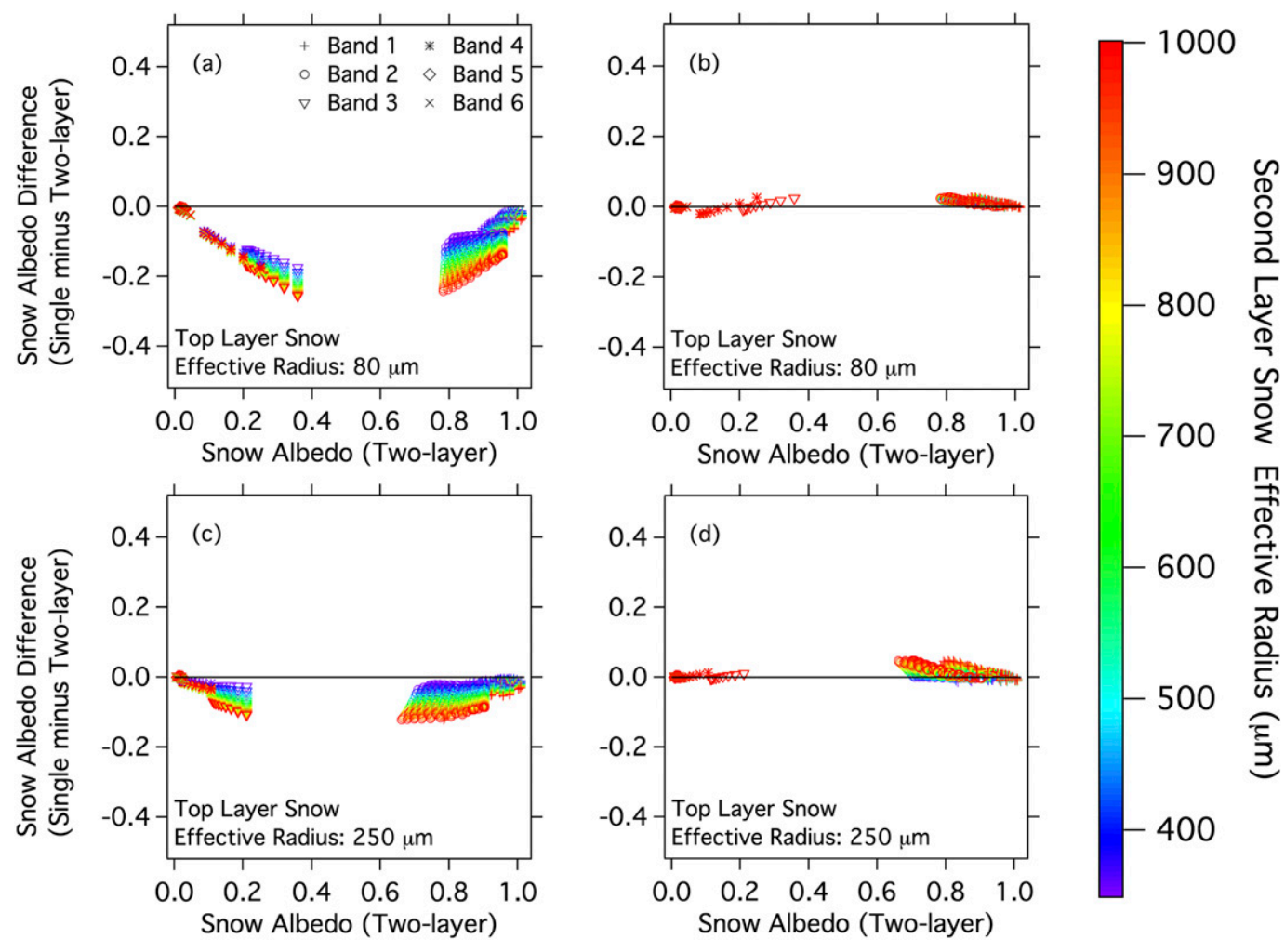

FIG. 13. Snow albedo differences associated with neglecting either the (left) top or (right) second snow layer, for each band of the NASA Langley Research Center's modified Fu-Liou broadband radiative transfer model, based on single-layer snow albedo parameterizations. Columns show cases with a snow particle effective radius of the top layer of (top) 80 and (bottom) $250 \mu \mathrm{m}$. The color of each data point indicates the snow particle effective radius of the second layer.

neglecting the top layer causes significant biases in the band snow albedo even for a 2-cm snow layer. However, neglecting the second snow layer provides less bias compared with neglecting the top layer, especially in infrared bands. In visible to near-infrared bands, the effects of neglecting the second layer is minimal for fresh snow since the corresponding optical thickness of the top snow layer with a small snow particle effective radius is large. However, as snow in the top layer metamorphoses into a larger snow particle effective radius, the corresponding optical thickness of the top layer decreases, and the optical properties of the second layer snow contribute more to the band snow albedo (Fig. 13d).

\section{Summary and conclusions}

This study developed a snow grain habit mixture (SGHM) model for snow particles in snow cover based on in situ snow measurements. The SGHM takes into account internally mixed $\mathrm{BC}$ in snow particles, snow particle habit fraction varying over the snow particle size domain, and snow PSDs depending on snow particle effective radius. The SGHM-based snow optical and microphysical property simulations are consistent with observations at visible wavelengths. The asymmetry parameter decreases with an increase in snow particle effective radius (I18) due to an increasing fraction of compact snow particles. Most previous studies assume a single snow particle shape over the entire size range, and are not capable of simulating the decrease of the asymmetry parameter with increasing particle sizes. The SGHM in conjunction with an adding-doubling radiative transfer model and observed snow microphysical property dataset (Grenfell et al. 1994) computes spectral snow albedos consistent with available observations.

Sensitivity studies reveal that when fresh snow covers an aged snow layer, top-snow-layer optical properties essentially determine the observed spectral snow albedo in the infrared spectral region. However, when the fresh snow is only approximately $1 \mathrm{~cm}$ deep or less (SWE $<1 \mathrm{~mm}$ ), small SWE variations in the top layer significantly change the snow albedo in the visible and near-infrared spectral region under polluted snow conditions. Spectral snow albedo is 
TABLE A1. Snow in situ measurement datasets used for the gamma fitting. The size definition in the third column includes the projectedarea-equivalent sphere radius $R_{A}$, maximum dimension $D$, or volume-equivalent sphere radius $R_{V}$. The particle shape in the fourth column includes a solid hexagonal column (SCOL) or droxtal (DROX).

\begin{tabular}{llcc}
\hline \hline & Information from original references & \multicolumn{2}{c}{ Treatment in this study } \\
\cline { 1 - 3 } Snow dataset ID & \multicolumn{1}{c}{ Representative particle shape } & Size definition & Particle shape \\
\hline A00, Feb22 & New snow + faceted crystal & $R_{A}$ & SCOL \\
A00, Feb23 & Faceted crystal + fine-grain old snow + depth hoar & $R_{A}$ & SCOL \\
A00, Feb24 & Faceted crystal + fine-grain old snow & $R_{A}$ & DROX \\
A00, Feb25 & Fine-grain old snow + granular snow & $R_{A}$ & DROX \\
N01, Fig. 5 & Dendritic new snow & $D$ & SCOL \\
N01, Fig. 8 & Compacted snow & $R_{A}$ & DROX \\
N01, Fig. 11 & Granular snow & $R_{A}$ & DROX \\
I18, Sample A & Fresh snow & $R_{V}$ & SCOL \\
I18, Sample B & Fresh snow & $R_{V}$ & SCOL \\
I18, Sample C & Granular snow & $R_{V}$ & DROX \\
I18, Sample D & Granular snow & $R_{V}$ & DROX \\
I18, Sample E & New snow & $R_{V}$ & SCOL \\
I18, Sample F & New snow & $R_{V}$ & SCOL \\
I18, Sample G & Compacted snow & $R_{V}$ & DROX \\
\hline
\end{tabular}

enhanced at large SZAs, and the magnitude of the snow albedo enhancement is a function of top-layer snow particle effective radius and internally mixed BC mass fraction.

We developed single-layer and two-layer snow albedo parameterizations for GCM applications, in six bands used in LaRC-FL RTM by regression fitting to rigorous snow albedo calculations based on the SGHM model. The single-layer snow albedo parameterization is a function of the snow particle effective radius, internally mixed BC mass fraction, and SZA. The two-layer snow albedo parameterization considers snow particle effective radii for a top (fresh snow) and second (aged snow) layer, SWE in the top layer, an internally mixed BC mass fraction in the two layers, and SZA. Both the singlelayer and two-layer parameterizations provide consistent broadband snow albedo compared to those from rigorous calculations, achieving correlation coefficients close to 0.99 for all bands. Note that applying these parameterizations to an extreme snow condition that is not included in the development of these parameterizations (e.g., $C_{\mathrm{BC}}$ far larger than $1000 \mathrm{ng} \mathrm{g}^{-1}$ ) may cause biases.

Comparing our single-layer snow albedo parameterization with the $\mathrm{He}$ et al. (2018c) parameterization based on sphere and Koch snowflake models, the present parameterization leads to higher snow albedos because the SGHM assumes that internally mixed BC and snow particles have a gamma PSD (note that $\mathrm{He}$ et al.'s BC and snow particles have uniform sizes), and the two parameterizations assume different snow particle shapes. Theoretical calculations reveal that with polluted snow, the snow albedo in visible wavelengths is sensitive to the PSD of internally mixed BC (He et al. 2018b) and is also sensitive to particle shape (He et al. 2018a). There is still a large gap in the understanding of the mixing state of black carbon in snow. Although this study considers BC in snow as $100 \%$ internally mixed, actual polluted snow particles may have both internal and external BC mixing. The absorption of externally mixed $\mathrm{BC}$ in snow is $50 \%$ of that of internally mixed BCs (e.g., Flanner et al. 2012), and a two-layer snow albedo parameterization based on $100 \%$ external mixing may also be useful and should be developed in the future. To improve snow property parameterization, it is necessary to carry out extensive in situ measurements of snow particle morphological characteristics. In particular, more direct snow in situ measurements targeting the $\mathrm{BC}$ mixing state will be helpful.

Sophisticated GCM snow-land surface schemes can resolve up to several snow layers, such as the Simplified Simple Biosphere, version 3 (SSiB-3; Xue et al. 1991, 2003), and a modified snow scheme in Noah (Saha et al. 2017). These schemes have been incorporated into regional climate models (Oaida et al. 2015). As shown in Fig. 13, ignoring a snow layer of few centimeters can induce nonnegligible biases in computed snow albedo, particularly in visible to near-infrared bands from 0.2 to $1.3 \mu \mathrm{m}$. The two-layer snow albedo parameterization in conjunction with a snow metamorphosis scheme (e.g., Niwano et al. 2012), or two-layer snow microphysical property retrievals based on satellite measurements (e.g., Jin et al. 2008) may be used to further reduce uncertainty in snow albedo associated with realistic snow layers and improve surface radiation budget estimations in GCMs. 
Acknowledgments. This work was partly supported by the NASA Clouds and the Earth's Radiant Energy System Project (Grant NNX17AB03G) and partly by the endowment funds related to the David Bullock Harris Chair in Geoscience at the College of Geosciences, Texas A\&M University (Grant 02-51223100001). Light-scattering computations and radiative transfer calculations were conducted at Texas A\&M Supercomputing Facilities, and the authors gratefully acknowledge facility staff for their help and assistance. The authors thank Dr. Guanglin Tang for help with computing the optical properties of snow particles.

\section{APPENDIX}

\section{PSD Fitting with Snow In Situ Measurement Datasets}

In the development of the PSD fit based on the gamma distribution, we use in situ measured PSD datasets from A00 (four datasets; see their Fig. 4), N01 (three datasets; their Figs. 5, 8, and 11), and I18 (seven datasets; their Fig. 5a). We manually read the number of particles for each bin from these figures. Although manual reading causes some uncertainty in snow PSDs, we assume that the uncertainty is small and does not induce a significant error in fitting of snow PSDs with the gamma distribution. Second, we unify the definition of the size bins among the 14 samples. A00 defines the projected-area-equivalent sphere radius as the snow particle size, and I18 uses the volume-equivalent sphere radius. In N01, the size definition differs among samples. For dendritic snow (Fig. 5 in N01), the longest column branch is defined as the diameter, and we treat the size definition as the maximum dimension. For other compact and granular particles (Figs. 8 and 11 in N01), each grain is assumed to be spheroid and the particle size is defined as $(a b)^{1 / 2}$ where $a$ and $b$ respectively indicate the major and minor diameter of an spheroid. However, quantitative values $a$ and $b$ for each sample are unavailable in N01. Therefore, we treat the size definition based on the spheroid assumption as projected-areaequivalent sphere radius.

In the size conversion, the snow particle shape is assumed to be SCOL for new and fresh snow and DROX for compacted, granular, and aged snow, as diagnosed in A00, N01, and I18. Table A1 lists the 14 snow particle sample datasets. In sample "A00, Feb24," we assume the particle shape to be DROX rather than SCOL because corresponding snow particle images suggest that the representative aspect ratio of particles seems to be close to unity. With these datasets and the method described in section $3 b$ [Eqs. (5) and (6)], we perform a

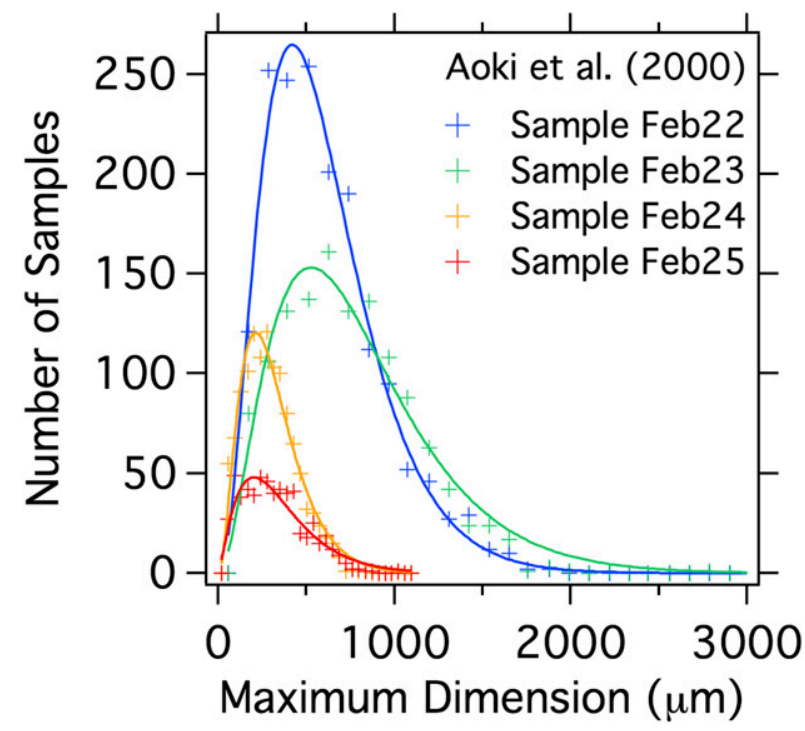

FIG. A1. Snow particle size distributions in terms of the maximum dimension for each snow in situ measurement obtained manually from Fig. 4 in A00. The locations of the symbols give the number of snow particle samples for each size bin. The colors of the symbols indicate snow dataset ID (for each day). The solid lines are the gamma distribution fits according to Eq. (5).

PSD fitting with each snow in situ measurement dataset. Figure A1 shows example PSD fittings based on the maximum dimension size definition using four A00 samples. The gamma distribution fits the snow PSD well. We perform the gamma distribution fitting for all snow in situ measurement datasets for each size definition (i.e., the maximum dimension and particle effective radius), which are used for snow PSD analysis as shown in Fig. 2.

\section{REFERENCES}

Aoki, T., T. Aoki, M. Fukabori, and A. Uchiyama, 1999: Numerical simulation of the atmospheric effects on snow albedo with a multiple scattering radiative transfer model for the atmosphere-snow system. J. Meteor. Soc. Japan, 77, 595-614, https://doi.org/10.2151/jmsj1965.77.2_595.

,,,-- A. Hachikubo, Y. Tachibana, and F. Nishio, 2000: Effects of snow physical parameters on spectral albedo and bidirectional reflectance of snow surface. J. Geophys. Res., 105, 10 219-10 236, https://doi.org/10.1029/1999JD901122.

_ - A. Hachikubo, and M. Hori, 2003: Effects of snow physical parameters on broadband albedos. J. Geophys. Res., 108, 4616, https://doi.org/10.1029/2003JD003506.

—_, K. Kuchiki, M. Niwano, Y. Kodama, M. Hosaka, and T. Tanaka, 2011: Physically based snow albedo model for calculating broadband albedos and the solar heating profile in snowpack for general circulation models. J. Geophys. Res., 116, D11114, https://doi.org/10.1029/2010JD015507.

Bi, L., P. Yang, C. Liu, B. Yi, B. A. Baum, B. van Diedenhoven, and H. Iwabuchi, 2014: Assessment of the accuracy of the conventional ray-tracing technique: Implications in remote 
sensing and radiative transfer involving ice clouds. J. Quant. Spectrosc. Radiat. Transfer, 146, 158-174, https://doi.org/10.1016/ j.jqsrt.2014.03.017.

Bond, T. C., and R. W. Bergstrom, 2006: Light absorption by carbonaceous particles: An investigative review. Aerosol Sci. Technol., 40, 27-67, https://doi.org/10.1080/02786820500421521.

Brandes, E. A., K. Ikeda, G. Zhang, M. Schonhuber, and R. M. Rasmussen, 2007: A statistical and physical description of hydrometeor distributions in Colorado snowstorms using a video disdrometer. J. Appl. Meteor. Climatol., 46, 634-650, https://doi.org/10.1175/JAM2489.1.

Carmagnola, C. M., and Coauthors, 2013: Snow spectral albedo at Summit, Greenland: Measurements and numerical simulations based on physical and chemical properties of the snowpack. Cryosphere, 7, 1139-1160, https://doi.org/10.5194/ tc-7-1139-2013.

Dang, C., R. E. Brandt, and S. G. Warren, 2015: Parameterizations for narrowband and broadband albedo of pure snow and snow containing mineral dust and black carbon. J. Geophys. Res. Atmos., 120, 5446-5468, https://doi.org/ 10.1002/2014JD022646.

_ Q. Fu, and S. G. Warren, 2016: Effect of snow grain shape on snow albedo. J. Atmos. Sci., 73, 3573-3583, https://doi.org/ 10.1175/JAS-D-15-0276.1.

_ , S. G. Warren, Q. Fu, S. J. Doherty, M. Sturm, and J. Su, 2017: Measurements of light-absorbing particles in snow across the Arctic, North America, and China: Effects on surface albedo. J. Geophys. Res. Atmos., 122, 10149-10 168, https://doi.org/ 10.1002/2017JD027070.

Doherty, S. J., S. G. Warren, T. C. Grenfell, A. D. Clarke, and R. Brandt, 2010: Light-absorbing impurities in Arctic snow. Atmos. Chem. Phys., 10, $11647-11680$, https://doi.org/10.5194/ acp-10-11647-2010.

Flanner, M. G., C. S. Zender, J. T. Randerson, and P. J. Rasch, 2007: Present-day climate forcing and response from black carbon in snow. J. Geophys. Res., 112, D11202, https://doi.org/ 10.1029/2006JD008003.

_- X. Liu, C. Zhou, J. E. Penner, and C. Jiao, 2012: Enhanced solar energy absorption by internally-mixed black carbon in snow grains. Atmos. Chem. Phys., 12, 4699-4721, https:// doi.org/10.5194/acp-12-4699-2012.

$\mathrm{Fu}, \mathrm{Q}$., and K. N. Liou, 1993: Parameterization of the radiative properties of cirrus clouds. J. Atmos. Sci., 50, 2008-2025, https://doi.org/10.1175/1520-0469(1993)050<2008:POTRPO > 2.0.CO;2.

Gardner, A. S., and M. J. Sharp, 2010: A review of snow and ice albedo and the development of a new physically based broadband albedo parameterization. J. Geophys. Res., 115, F01009, https://doi.org/10.1029/2009JF001444.

Grenfell, T. C., S. G. Warren, and P. C. Mullen, 1994: Reflection of solar radiation by the Antarctic snow surface at ultraviolet, visible, and near-infrared wavelengths. J. Geophys. Res., 99, 18 669-18 684, https://doi.org/10.1029/94JD01484.

Hansen, J., and L. Travis, 1974: Light scattering in planetary atmospheres. Space Sci. Rev., 16, 527-610, https://doi.org/10.1007/ BF00168069.

—_, and L. Nazarenko, 2004: Soot climate forcing via snow and ice albedos. Proc. Natl. Acad. Sci. USA, 101, 423-428, https://doi.org/10.1073/pnas.2237157100.

He, C., Y. Takano, and K. N. Liou, 2017a: Close packing effects on clean and dirty snow albedo and associated climatic implications. Geophys. Res. Lett., 44, 3719-3727, https://doi.org/ 10.1002/2017GL072916.
,,,--- P. Yang, Q. Li, and F. Chen, 2017b: Impact of snow particle shape and black carbon-snow internal mixing on snow optical properties: Parameterizations for climate models. J. Climate, 30, 10 019-10 036, https://doi.org/10.1175/ JCLI-D-17-0300.1.

, M. G. Flanner, F. Chen, M. Barlage, K. N. Liou, S. Kang, J. Ming, and Y. Qian, 2018a: Black carbon-induced snow albedo reduction over the Tibetan Plateau: Uncertainties from snow grain shape and aerosol-snow mixing state based on an updated SNICAR model. Atmos. Chem. Phys., 18, $11507-$ 11 527, https://doi.org/10.5194/acp-18-11507-2018.

, K. N. Liou, and Y. Takano, 2018b: Resolving size distribution of black carbon internally mixed with snow: Impact on snow optical properties and albedo. Geophys. Res. Lett., 45, 26972705, https://doi.org/10.1002/2018GL077062.

,,,--- P. Yang, L. Qi, and F. Chen, 2018c: Impact of grain shape and multiple black carbon internal mixing on snow albedo: Parameterization and radiative effect analysis. J. Geophys. Res. Atmos., 123, 1253-1268, https://doi.org/10.1002/2017JD027752.

Huang, X., P. Yang, G. Kattawar, and K. N. Liou, 2015: Effect of mineral dust aerosol aspect ratio on polarized reflectance. J. Quant. Spectrosc. Radiat. Transfer, 151, 97-109, https:// doi.org/10.1016/j.jqsrt.2014.09.014.

Ishimoto, H., S. Adachi, S. Yamaguchi, T. Tanikawa, T. Aoki, and K. Masuda, 2018: Snow particles extracted from X-ray computed microtomography imagery and their single-scattering properties. J. Quant. Spectrosc. Radiat. Transfer, 209, 113-128, https://doi.org/10.1016/j.jqsrt.2018.01.021.

Iwabuchi, H., P. Yang, K. N. Liou, and P. Minnis, 2012: Physical and optical properties of persistent contrails: Climatology and interpretation. J. Geophys. Res., 117, D06215, https://doi.org/ 10.1029/2011JD017020.

Jin, Z., T. P. Charlock, P. Yang, Y. Xie, and W. Miller, 2008: Snow optical properties for different particles shapes with application to snow grain size retrieval and MODIS/CERES radiance comparison over Antarctica. Remote Sens. Environ., 112, 3563-3581, https://doi.org/10.1016/j.rse.2008.04.011.

Kato, S., T. P. Ackerman, J. H. Mather, and E. E. Clothiaux, 1999: The $k$-distribution method and correlated- $k$ approximation for a shortwave radiative transfer model. J. Quant. Spectrosc. Radiat. Transfer, 62, 109-121, https://doi.org/ 10.1016/S0022-4073(98)00075-2.

- F. G. Rose, and T. P. Charlock, 2005: Computation of domain-averaged irradiance using satellite-derived cloud properties. J. Atmos. Oceanic Technol., 22, 146-164, https://doi.org/ 10.1175/JTECH-1694.1.

Kikuchi, K., T. Kameda, K. Higuchi, and A. Yamashita, 2013: A global classification of snow crystals, ice crystals, and solid precipitation based on observations from middle latitudes to polar regions. Atmos. Res., 132-133, 460-472, https://doi.org/ 10.1016/j.atmosres.2013.06.006.

Kratz, D. P., and F. G. Rose, 1999: Accounting for molecular absorption within the spectral range of the CERES window channel. J. Quant. Spectrosc. Radiat. Transfer, 61, 83-95, https://doi.org/10.1016/S0022-4073(97)00203-3.

Liou, K. N., Y. Takano, C. He, P. Yang, L. R. Leung, Y. Gu, and W. L. Lee, 2014: Stochastic parameterization for light absorption by internally mixed $\mathrm{BC} /$ dust in snow grains for application to climate models. J. Geophys. Res. Atmos., 119, 7616-7632, https://doi.org/10.1002/2014JD021665.

Macke, A., M. I. Mishchenko, and B. Cains, 1996: The influence of inclusions on light scattering by large ice particles. J. Geophys. Res., 101, 23 311-23 316, https://doi.org/10.1029/96JD02364. 
Marshall, S. E., 1989: A physical parameterization of snow albedo for use in climate models. NCAR Cooperative thesis 123 , $175 \mathrm{pp}$.

— GCMs. Part 1: Snow cover fraction, albedo, grain size, and age. Climate Dyn., 10, 21-37, https://doi.org/10.1007/BF00210334.

Mishchenko, M. I., V. P. Tishkovets, L. D. Travis, B. Cairns, J. M. Dlugach, L. Liu, V. K. Rosenbush, and N. N. Kiselev, 2011: Electromagnetic scattering by a morphologically complex object: Fundamental concepts and common misconceptions. J. Quant. Spectrosc. Radiat. Transfer, 112, 671-692, https:// doi.org/10.1016/j.jqsrt.2010.03.016.

Molod, A., L. Takacs, M. Suaìrez, and J. Bacmeister, 2015: Development of the GEOS-5 atmospheric general circulation model: Evolution from MERRA to MERRA2. Geosci. Model Dev., 8, 1339-1356, https://doi.org/10.5194/gmd-8-1339-2015.

Nakamura, T., O. Abe, T. Hasegawa, R. Tamura, and T. Ohta, 2001: Spectral reflectance of snow with a known particle-size distribution in successive metamorphism. Cold Reg. Sci. Technol., 32, 13-26, https://doi.org/10.1016/S0165-232X(01) 00019-2.

Niwano, M., T. Aoki, K. Kuchiki, M. Hosaka, and Y. Kodama, 2012: Snow Metamorphism and Albedo Process (SMAP) model for climate studies: Model validation using meteorological and snow impurity data measured at Sapporo, Japan. J. Geophys. Res., 117, F03008, https://doi.org/10.1029/ 2011JF002239.

Nolin, A. W., and J. Dozier, 2000: A hyperspectral method for remotely sensing the grain size of snow. Remote Sens. Environ., 74, 207-216, https://doi.org/10.1016/S0034-4257(00)00111-5.

Oaida, C. M., Y. Xue, M. G. Flanner, S. M. Skiles, F. De Sales, and T. H. Painter, 2015: Improving snow albedo processes in $\mathrm{WRF} / \mathrm{SSiB}$ regional climate model to assess impact of dust and black carbon in snow on surface energy balance and hydrology over western U.S. J. Geophys. Res. Atmos., 120, 3228-3248, https://doi.org/10.1002/2014JD022444.

Ohtake, T., and T. Yogi, 1979: Winter ice crystals at the South Pole. Antarct. J. U. S., 14, 201-203.

Picard, G., L. Arnaud, F. Domine, and M. Fily, 2009: Determining snow specific surface area from near-infrared reflectance measurements: Numerical study of the influence of particle shape. Cold Reg. Sci. Technol., 56, 10-17, https://doi.org/ 10.1016/j.coldregions.2008.10.001.

Randall, D., and Coauthors, 1994: Analysis of snow feedbacks in 14 general circulation models. J. Geophys. Res., 99, $20757-$ 20 771, https://doi.org/10.1029/94JD01633.

Saha, S. K., K. Sujith, S. Pokhrel, H. S. Chaudhari, and A. Hazra, 2017: Effects of multilayer snow scheme on the simulation of snow: Offline Noah and coupled with NCEP CFSv2. J. Adv. Model. Earth Syst., 9, 271-290, https://doi.org/10.1002/ 2016MS000845.

Schwarz, J. P., R. S. Gao, A. E. Perring, J. R. Spackman, and D. W. Fahey, 2013: Black carbon aerosol size in snow. Sci. Rep., 3, 1356, https://doi.org/10.1038/srep01356.

Stegmann, P. G., and P. Yang, 2017: A regional, size-dependent, and causal effective medium model for Asian and Saharan mineral dust refractive index spectra. J. Aerosol Sci., 114, 327341, https://doi.org/10.1016/j.jaerosci.2017.10.003.

Tang, G., R. L. Panetta, P. Yang, G. L. Kattawar, and P. W. Zhai, 2017: Effect of ice crystal surface roughness and air bubble inclusions on cirrus cloud radiative properties from remote sensing perspective. J. Quant. Spectrosc. Radiat. Transfer, 195, 119-131, https://doi.org/10.1016/j.jqsrt.2017.01.016.
Walden, V. P., S. G. Warren, and E. Tuttle, 2003: Atmospheric ice crystals over the Antarctic plateau in winter. J. Appl. Meteor., 42, 1391-1405, https://doi.org/10.1175/1520-0450(2003) 042<1391:AICOTA > 2.0.CO;2.

Wang, X., S. J. Doherty, and J. Huang, 2013: Black carbon and other light-absorbing impurities in snow across northern China. J. Geophys. Res. Atmos., 118, 1471-1492, https://doi.org/ 10.1029/2012JD018291.

Warren, S. G., 1982: Optical properties of snow. Rev. Geophys., 20, 67-89, https://doi.org/10.1029/RG020i001p00067.

— of snow. II: Snow containing atmospheric aerosols. J. Atmos. Sci., 37, 2734-2745, https://doi.org/10.1175/1520-0469(1980) 037<2734:AMFTSA > 2.0.CO;2.

_ traviolet to the microwave: A revised compilation. J. Geophys. Res., 113, D14220, https://doi.org/10.1029/2007JD009744.

Wiscombe, W. J., and S. G. Warren, 1980: A model for the spectral albedo of snow. I: Pure snow. J. Atmos. Sci., 37, 2712-2733, https://doi.org/10.1175/1520-0469(1980)037<2712: AMFTSA $>2.0 . \mathrm{CO} ; 2$.

Xue, Y., P. J. Sellers, J. L. Kinter, and J. Shukla, 1991: A simplified model for global climate studies. J. Climate, 4, 345-364, https:// doi.org/10.1175/1520-0442(1991)004<0345:ASBMFG >2.0.CO;2.

_, S. Sun, D. S. Kahan, and Y. Jiao, 2003: Impact of parameterizations in snow physics and interface processes on the simulation of snow cover and runoff at several cold region sites. J. Geophys. Res., 108, 8859, https://doi.org/10.1029/2002JD003174.

Yang, P., and K. N. Liou, 1998: Single-scattering properties of complex ice crystals in terrestrial atmosphere. Contrib. Atmos. Phys., 71, 223-248.

- B. A. Baum, A. J. Heymsfield, Y.-X. Hu, H.-L. Huang, S.-C. Tsay, and S. A. Ackerman, 2003: Single scattering properties of droxtals. J. Quant. Spectrosc. Radiat. Transfer, 79-80, 11591169, https://doi.org/10.1016/S0022-4073(02)00347-3.

— L. Bi, B. A. Baum, K. N. Liou, G. L. Kattawar, M. I. Mishchenko, and B. Cole, 2013: Spectrally consistent scattering, absorption, and polarization properties of atmospheric ice crystals at wavelengths from 0.2 to $100 \mu \mathrm{m}$. J. Atmos. Sci., 70, 330-347, https://doi.org/10.1175/JAS-D-12-039.1.

— J. Ding, R. L. Panetta, K.-N. Liou, G. W. Kattawar, and M. I. Mishchenko, 2019: On the convergence of numerical computations for both exact and approximate solutions for electromagnetic scattering by nonspherical dielectric particles. Prog. Electromagn. Res., 164, 27-61, http://www.jpier.org/PIER/ pier.php?paper $=18112810$.

Yasunari, T. J., R. D. Koster, K.-M. Lau, T. Aoki, Y. C. Sud, T. Yamazaki, H. Motoyoshi, and Y. Kodama, 2011: Influence of dust and black carbon on the snow albedo in the NASA Goddard Earth Observing System version 5 land surface model. J. Geophys. Res., 116, D02210, https://doi.org/10.1029/ 2010JD014861.

Zhang, Y., and Coauthors, 2018: Black carbon and mineral dust in snow cover on the Tibetan Plateau. Cryosphere, 12, 413-431, https://doi.org/10.5194/tc-12-413-2018.

Zhang, Z., P. Yang, G. W. Kattawar, S.-C. Tsay, B. A. Baum, Y. Hu, A. J. Heymsfield, and J. Reichardt, 2004: Geometricaloptics solution to light scattering by droxtal ice crystals. Appl. Opt., 43, 2490-2499, https://doi.org/10.1364/AO.43.002490.

Zhou, X., S. Li, and K. Stamnes, 2003: Effects of vertical inhomogeneity on snow spectral albedo and its implication for optical remote sensing of snow. J. Geophys. Res., 108, 4738, https://doi.org/10.1029/2003JD003859. 